بررسى آزمايشخاهى تأثير آبشكنهاى آرمور ساده و L شكل در بالادست و ياييندست آبخير، بر هيدروليك جريان رودخانه و دبى انحر افى آبخير به كمك مدل فيزيكى

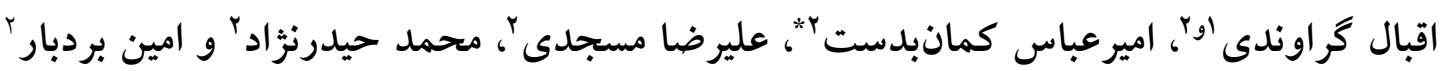

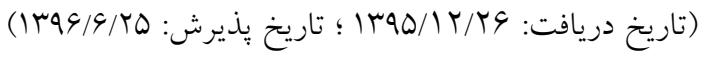

جكيده

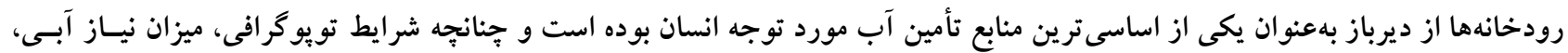

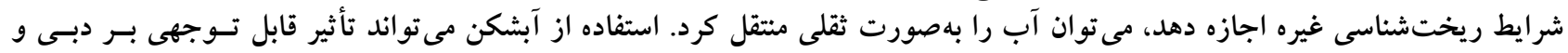

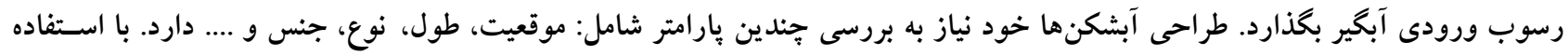

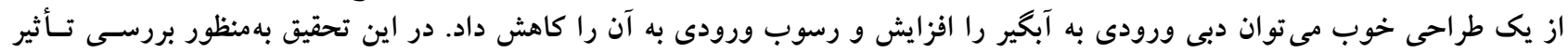

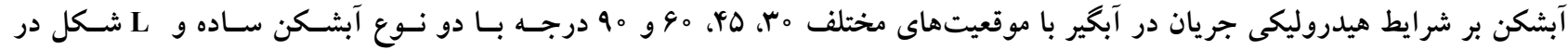

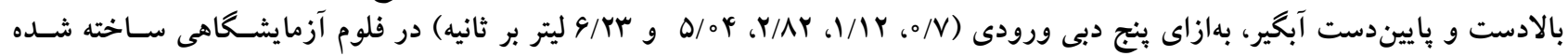

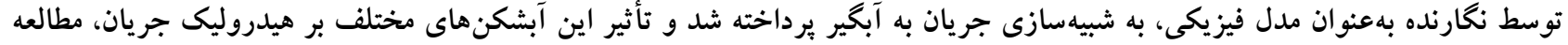

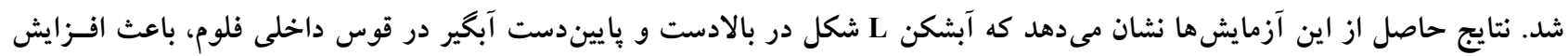

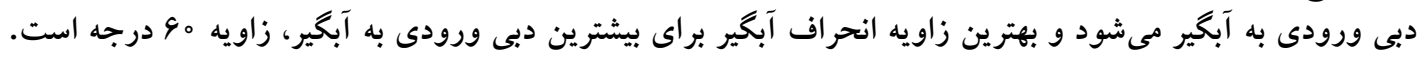

وارههاى كليدى: آبحير، آبشكن، مدل فيزيكى، زاويه انحراف، هيدروليك جريان، شبيهازى

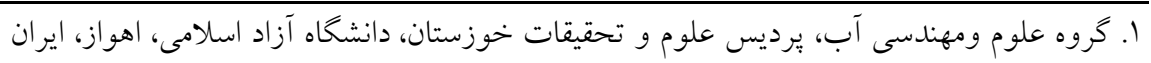

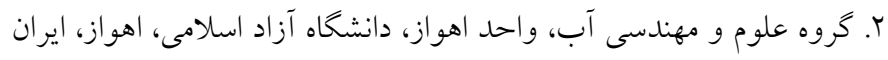

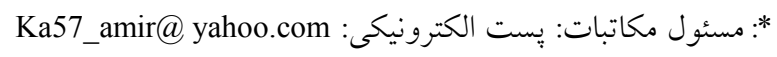




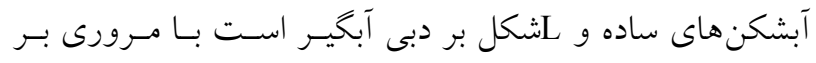

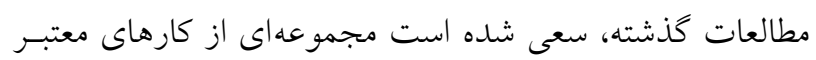

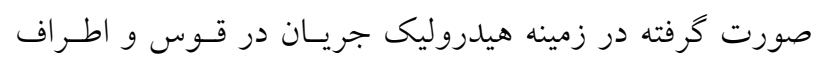

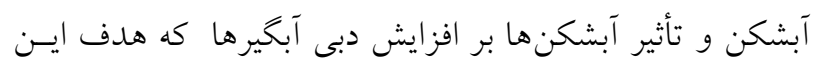

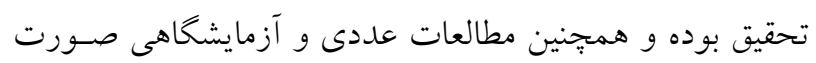

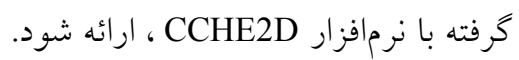
اسماعيلنزاد، با ساختن يك ميكرومدل، هيدروليك جريـان

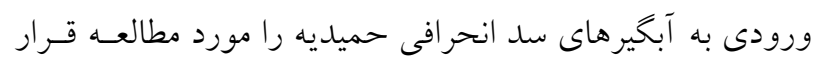

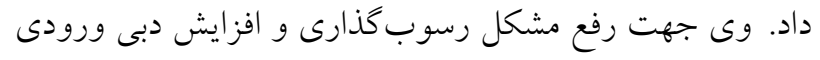

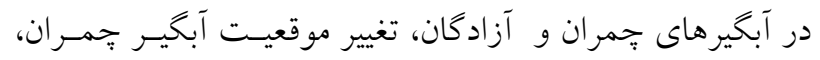

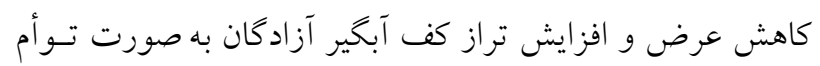
را مناسبترين كزينه معرفى كرد (Y).

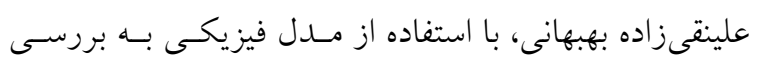

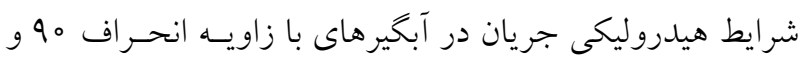

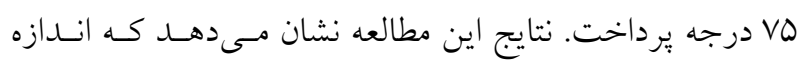

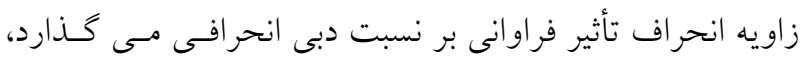

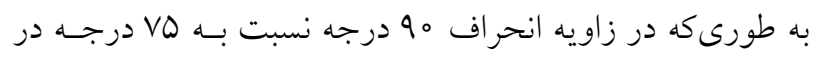

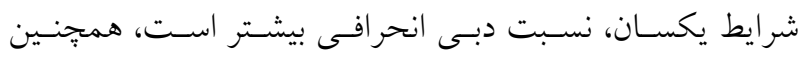

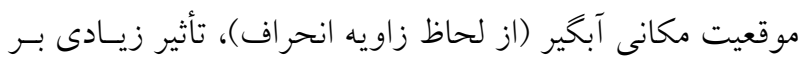

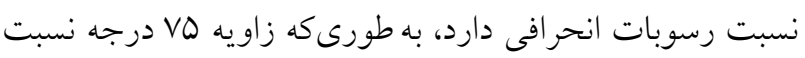

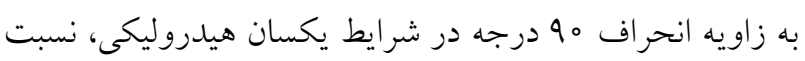
رسوبات انحراف كمترى را شامل مىشود (Y). تائبى و همكاران، نيز شبيه سازى عددى جريان را در قـوس سوس سوس

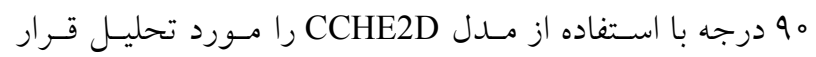

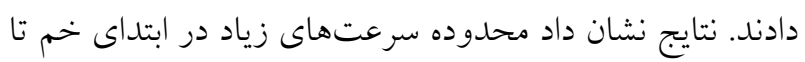
زاويه 0ه درجه قوس در قسمت ديواره داخلى فلوم اسـت و ازئل

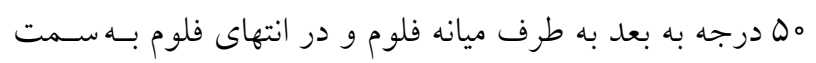

ديواره خارجى منحرف مىشود (r).

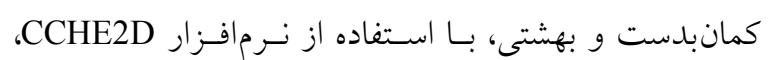

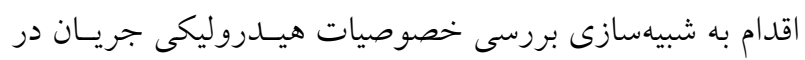

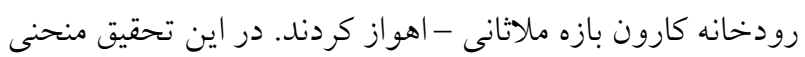

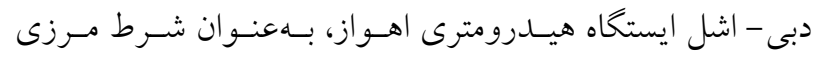

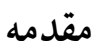

يكى از قديمىترين و در عين حال ارزانترين روشهاى استفاده

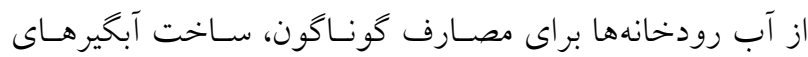

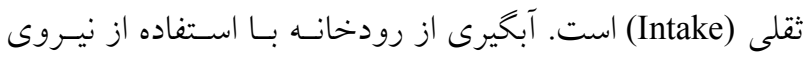

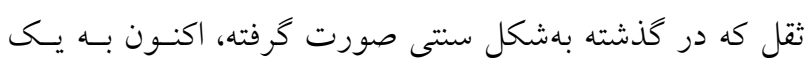

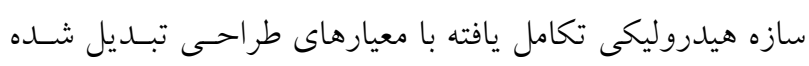

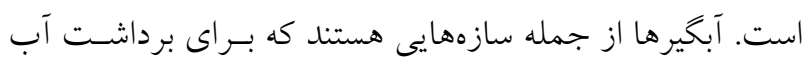

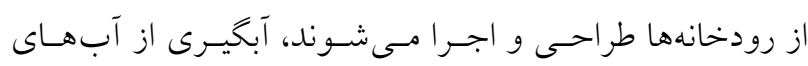

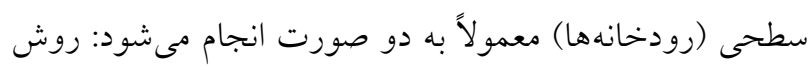

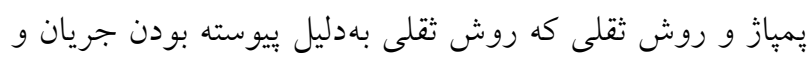

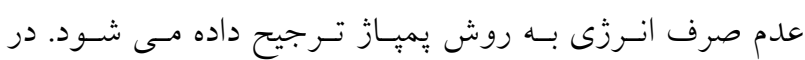
برداشت آب به روش ثقلى از سه نوع آبخير مى توان استفاده كرد

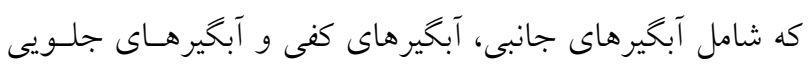

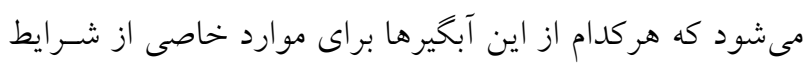

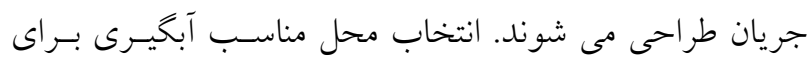

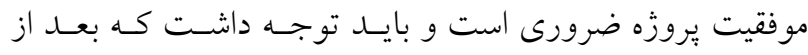

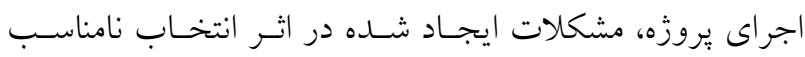

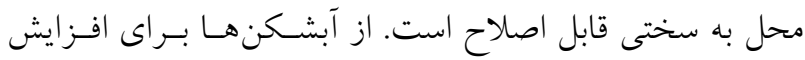
دبى ورودى به آبخيرها استفاده مى هود.

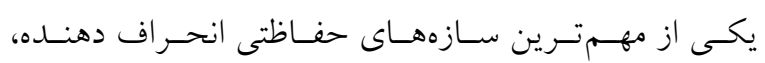

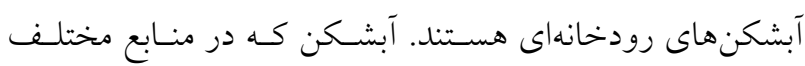

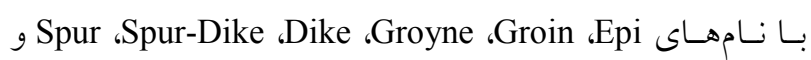
Jetteis از آن ياد مىشود، عبارت است از سازهاى سنكى، بتنى،

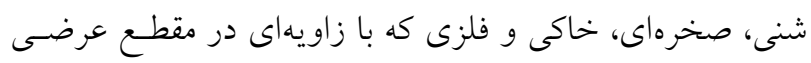

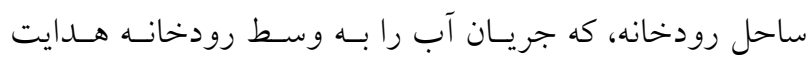

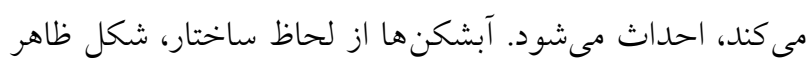

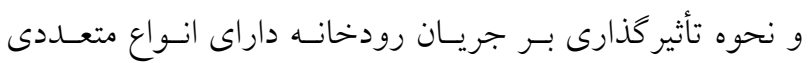

هستند (شكل (1). در اين تحقيق از آبشكنهاى ساده و L شكل استفاده شد كه

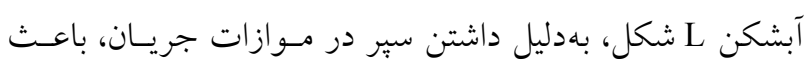

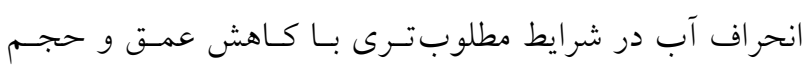
آبشستخى، به طرف آبخير مى شـود هــدف از ايسن تحقيـق تـأثير 


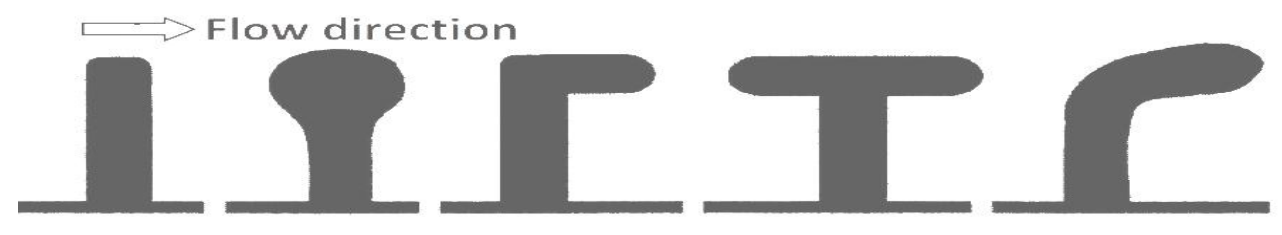

شكل l. تقسيمبندى آبشكنها از نظر شكل هندسى (سازمان مديريت و برنامهريزى، Yo Y )

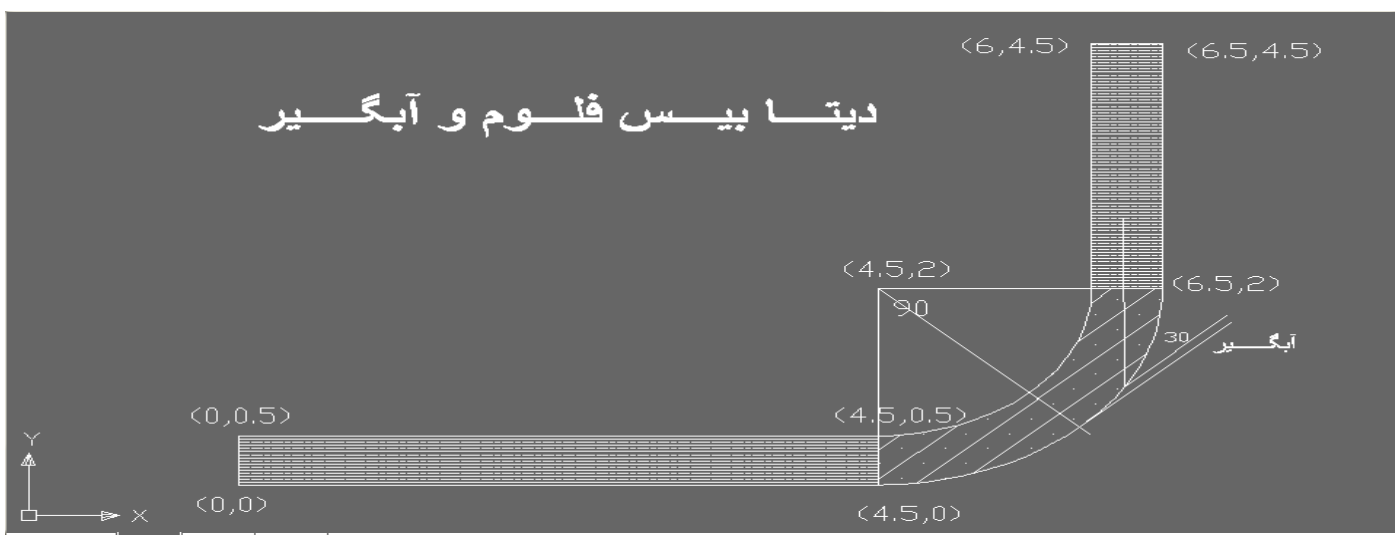

شكل r. نقشه فلوم و آبخير آزمايشگاهى ساخته شده توسط نخارنده

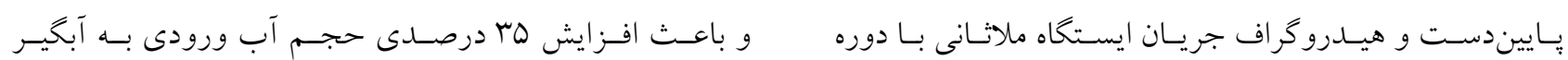

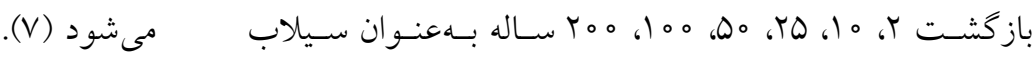
طراحى شـرط مـرزى بالادسـت اسـتفاده شـــ و اجـراى مـــل

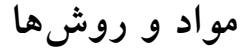

در اين تحقيـق، اثـر وجـود آبشـكنهـاى سـاده و L شـكل در بالادست و بِاييندست آبخير، در مقدار دبى آبخير بــا اسـتفاده از

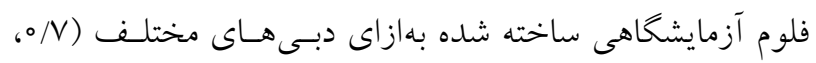
Y I/T

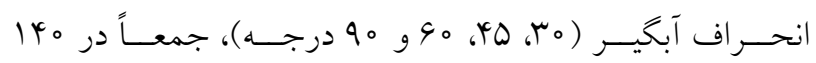
آزمايش بررسى شد. براى بررسى آزمايشخاهى اين تحقيـق، فلـومى برابـر نقشـهـ (شكل r)، مشخصات فلـوم، (جــول () و تصـوير كلسى فلـوم (شكل ب و ץ)، در دانشخاه آزاد واحد اهواز توسط نخارنـده، در دستور ساخت قرار كرفـت كـه كانسالهـاى ورودى و خروجـى فلوم، روباز مستطيلى با جداره ورق يلكسى كالاس به ضـخامت

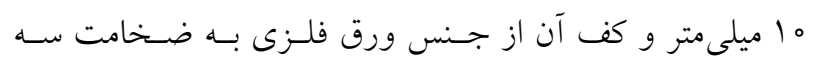

بهصورت غير ماندگار حداكثر رقوم آب بهدست آمد. براى نمونه مقادير رقوم سطح آب، برايند سـرعت، دبسى در واحسد عـرض،

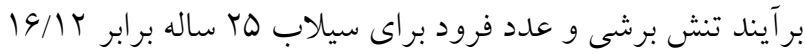

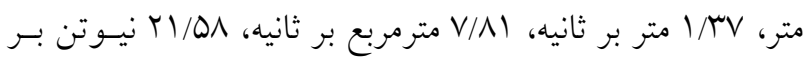
مجذور ثانيه و •//ه براورده شده است (9). منادى زاده، به بررسى آزمايشخاهى تأثير آبشكن بر الخــوى

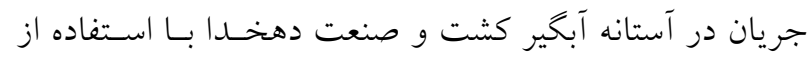
ميكرومدل يرداخت. براى اين منظور در آزمايشخاه ميكرومدلى

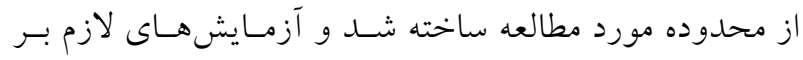

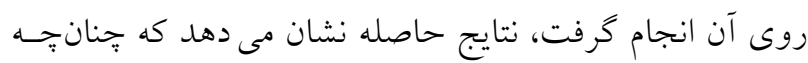
آبشكن در فاصلهاى به اندازه عرض رودخانه در دهانـه آبخيـر به فاصله بی مترى از مركز آبخير در بالادست آن احداث شود، آبشكن بيشترين تأثير را بر دبى ورودى به آبخير خواهد داشت 
نشريه علوم آب و خاك (علوم و فنون كشاورزى و منابع طبيعى) / سال بيست و دو / شماره سوم / پاييز IrqV

جدول ا. مشخصات فلوم

\begin{tabular}{|c|c|c|c|c|c|c|}
\hline دبى هاى مورد استفاده & زاويه قوس & ارتفاع كانال & عرض كانال & شعاع انحناء & طول كانال خروجى & طول كانال ورودى \\
\hline (ليتر بر ثانيه) & ( درجه ) & \multicolumn{5}{|c|}{ (متر) } \\
\hline 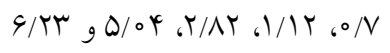 & 90 & $0 / 9$ & $\circ / 0$ & $r$ & $r / Q$ & $\varphi / \Delta$ \\
\hline
\end{tabular}

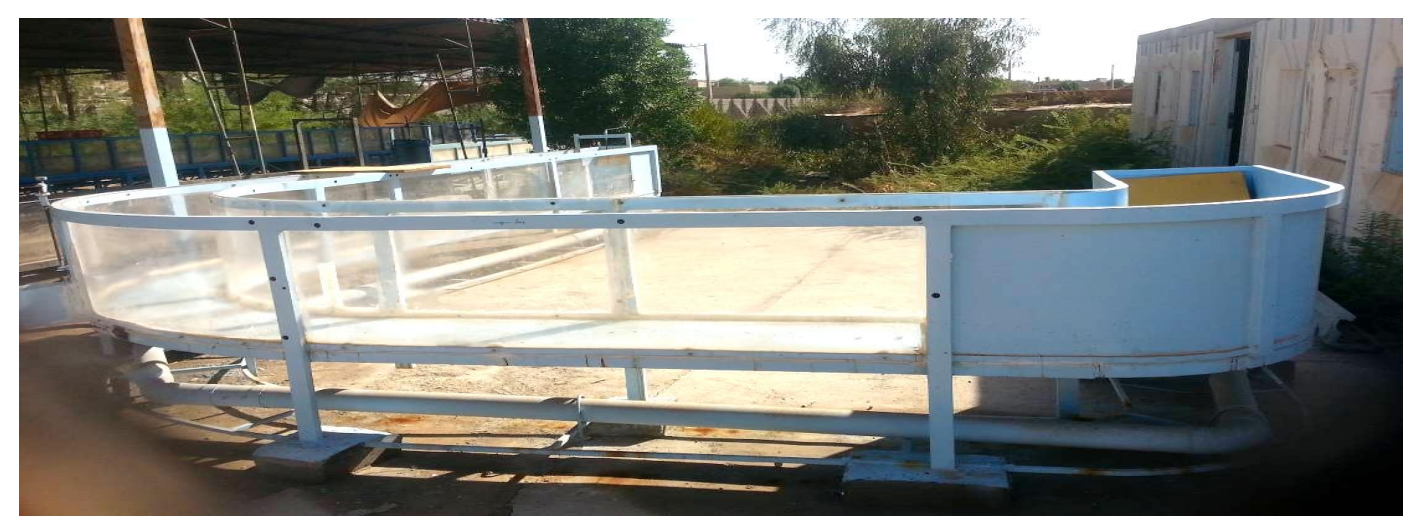

شكل r. فلوم آزمايشخاهى ساخته شده جهت تحقيق انجام شده توسط نخارنده

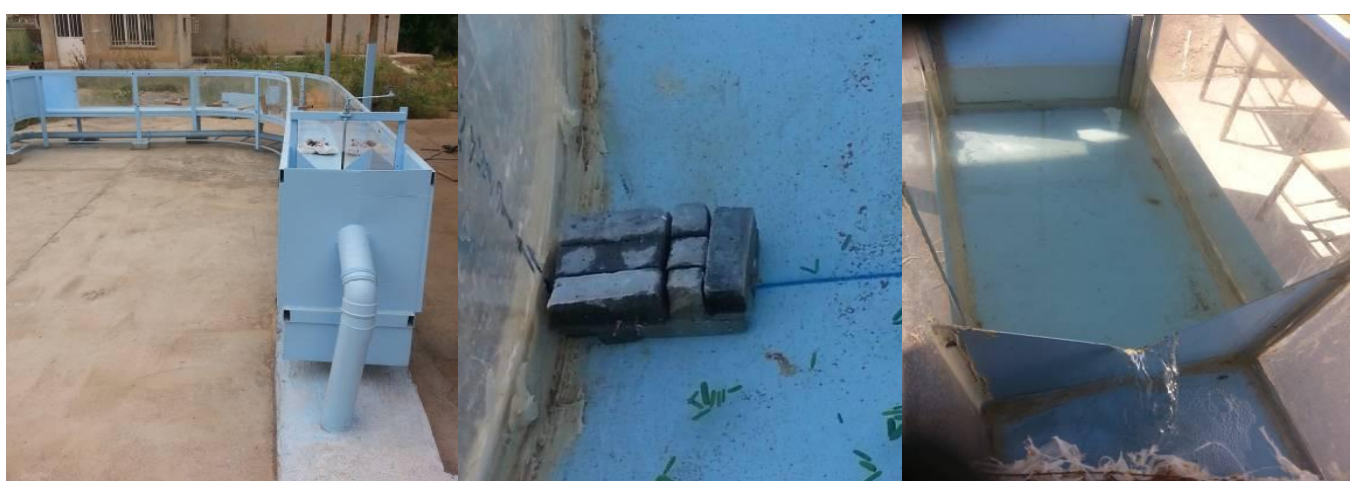

شكل †. تصاوير وسايل و تجهيزات فلوم ساخته شده تحقيق

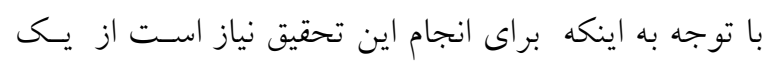

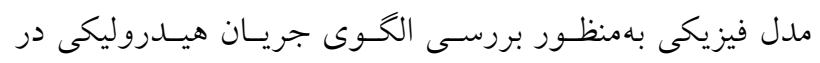

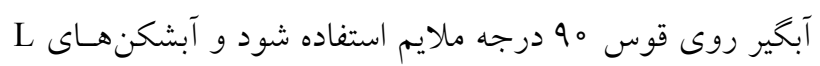

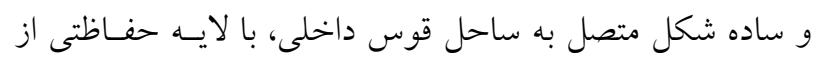

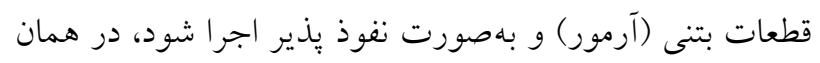

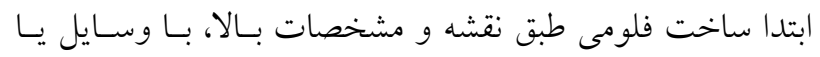

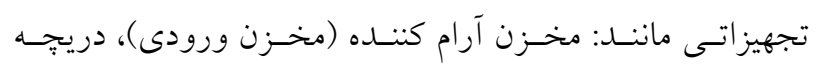
كشويى براى كترل و تنظيم سطح آب، سرريز مثلثى ورودى و و

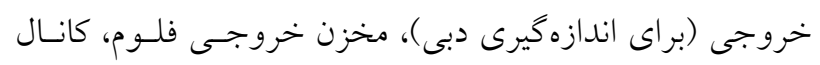

ميلى متر است، بهطورى كه كه طول كانالهاى مستقيم ورودى در

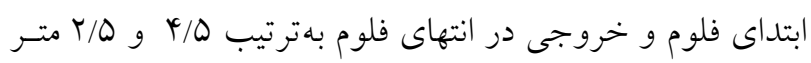

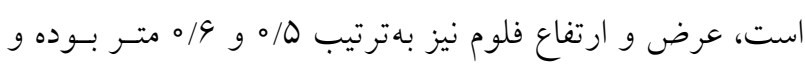

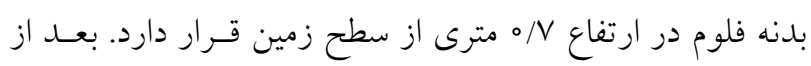

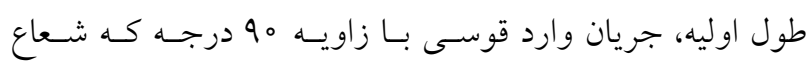

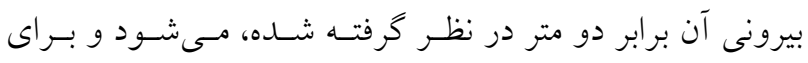

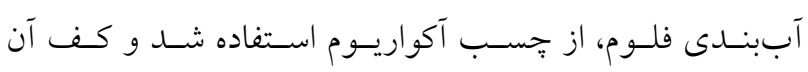

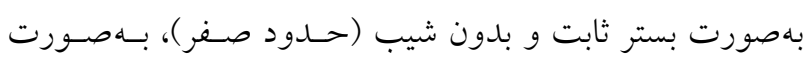
افقى ساخته شده است. 
جدول r. نحوه آزمايشها با دبىها و زواياى مختلف

\begin{tabular}{|c|c|c|c|c|c|c|}
\hline دبى فلوم (L/S) & زاويه آبخير & \multicolumn{2}{|c|}{ آبشكنهاى قائم بالادست } & \multicolumn{2}{|c|}{ آبشكن هاى قائم باييندست } & بـ آبخير (L/S) \\
\hline Q & $\alpha$ & آبشكن L L & آبشكن ساده & L آبشكن L & آبشكن ساده & Qd \\
\hline $\mathrm{Q}_{1}$ & & $\checkmark$ & $\checkmark$ & $\checkmark$ & $\checkmark$ & \\
\hline$Q_{r}$ & , & $\checkmark$ & $\checkmark$ & $\checkmark$ & $\checkmark$ & \\
\hline $\mathrm{Q}_{r}$ & $a_{r}$ & $\checkmark$ & $\checkmark$ & $\checkmark$ & $\checkmark$ & \\
\hline $\mathrm{Q}_{\psi}$ & $\alpha_{\mathrm{c}}$ & $\checkmark$ & $\checkmark$ & $\checkmark$ & $\checkmark$ & \\
\hline $\mathrm{Q}_{\Delta}$ & & $\checkmark$ & $\checkmark$ & $\checkmark$ & $\checkmark$ & \\
\hline
\end{tabular}

در رابطه (1)، p جرم مخصوص سيال، ب لزجـت سـيال، و

شتاب ثقل، y عمق جريان در كانال اصلى، V سرعت جريـان،

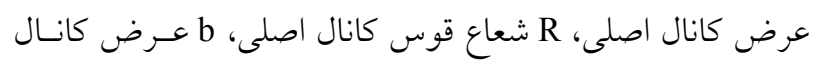

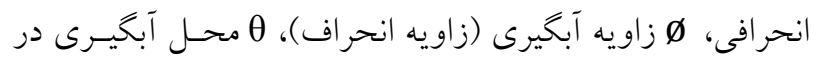

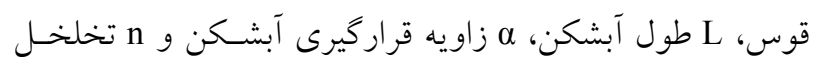

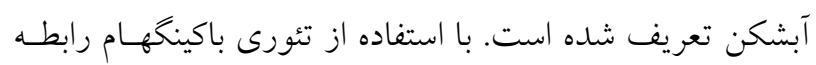

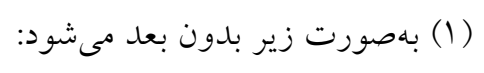

$\mathrm{Q}_{\mathrm{r}}=\frac{\mathrm{Q}_{\mathrm{D}}}{\mathrm{Q}_{\mathrm{m}}}=\mathrm{f}\left(\mathrm{Re}, \mathrm{Fr}, \frac{\mathrm{y}}{\mathrm{B}}, \frac{\mathrm{R}}{\mathrm{B}}, \frac{\mathrm{b}}{\mathrm{B}}, \frac{\mathrm{L}}{\mathrm{B}}, \varphi, \theta, \alpha, \mathrm{n}\right)$

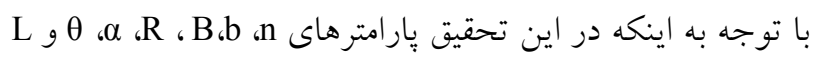

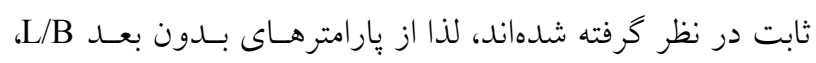

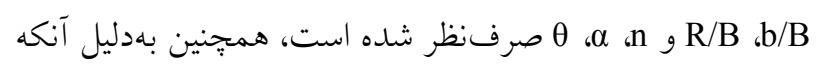

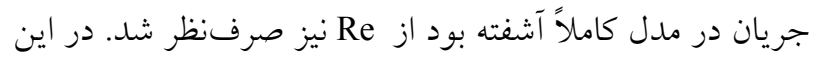

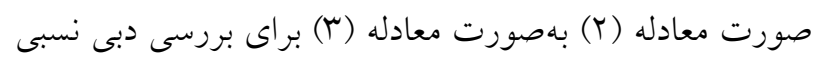
$\mathrm{Q}_{\mathrm{r}}=\frac{\mathrm{Q}_{\mathrm{D}}}{\mathrm{Q}_{\mathrm{m}}}=\left(\mathrm{Fr}, \frac{\mathrm{y}}{\mathrm{B}}, \varphi\right)$ انحر اف شده، ساده مىشود.

آزمايش هاى اصلى مدل

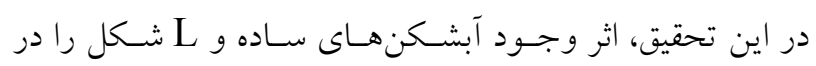

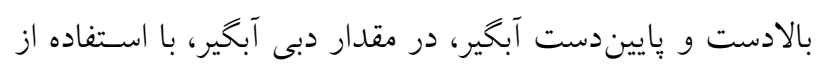

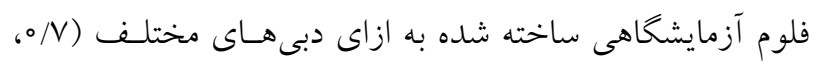

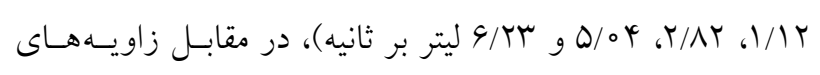

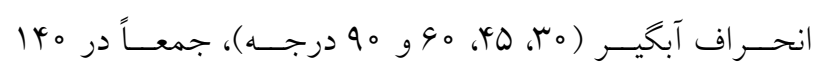

آبخير با دريجه، بمٍِ انتقال آب به فلوم، مخزن زمينى انبار آب،

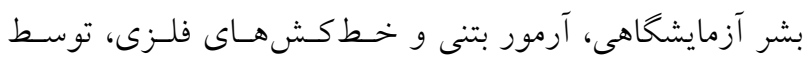
نويسندكان انجام شد.

\section{روش انجام تحقيق}

كاليبره كردن مدل

براى كاليبره كردن مدل فيزيكى اين تحقيق، نمودار دبى - اشـل مدرد

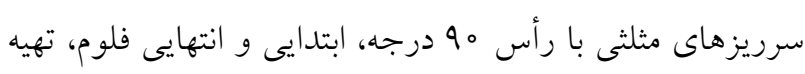

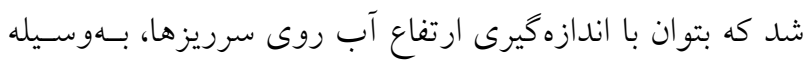

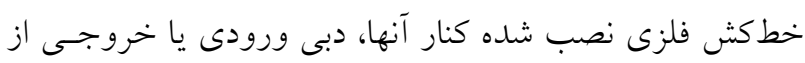

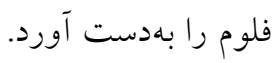

استخر اج اعداد بدون بعد

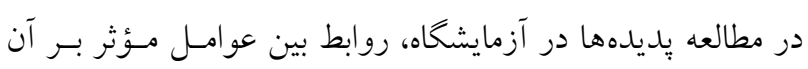

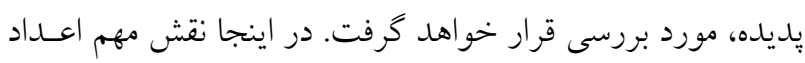

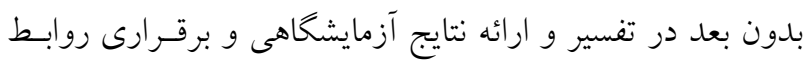

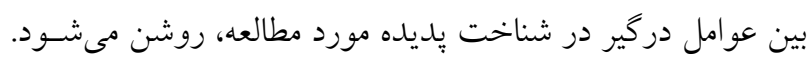

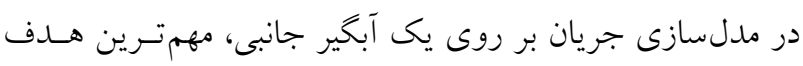
تعيين مقدار دبى منحرف شده در شرايط مختلف جريان در كانال

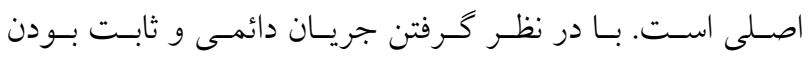

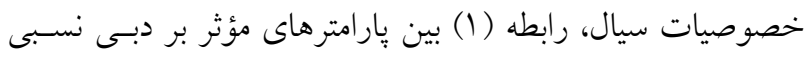
انحرافى در حالت تعادل برقرار است: $\mathrm{Q}_{\mathrm{r}}=\frac{\mathrm{Q}_{\mathrm{D}}}{\mathrm{Q}_{\mathrm{m}}}=\mathrm{f}(\rho, \mu, \mathrm{g}, \mathrm{y}, \mathrm{V}, \mathrm{B}, \mathrm{R}, \mathrm{b}, \varphi, \theta, \mathrm{L}, \alpha, \mathrm{n})$ 

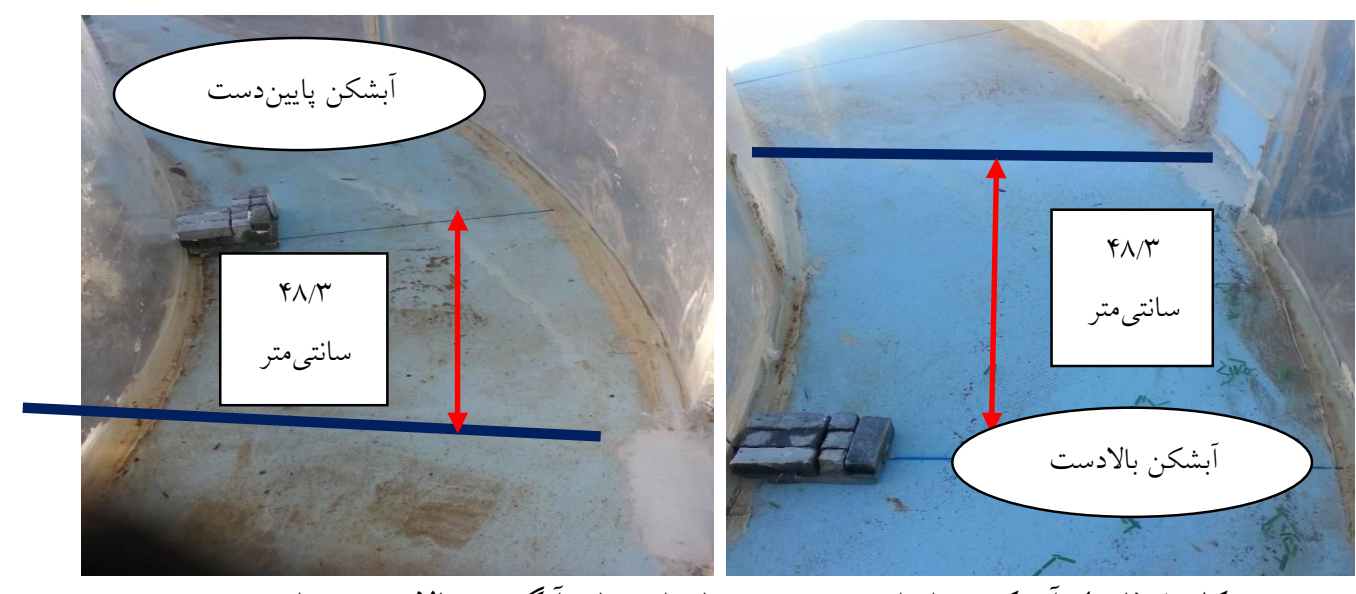

شكل ه. فاصله آبشكن به اندازه عرض رودخانه از دهانه آبكير در بالادست و باييندست

ورودى به آبخير دارد، (در فلوم مـورد آزمـايش ايسن تحقيـق برابـر

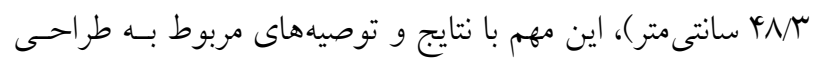

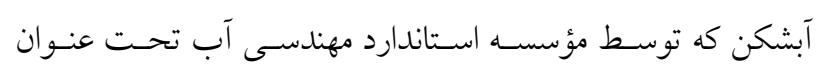

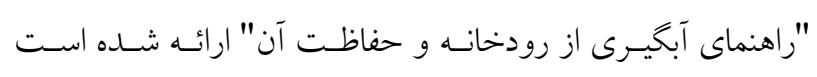

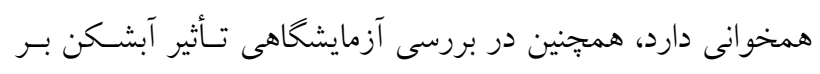

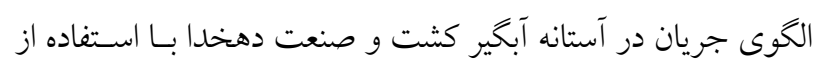

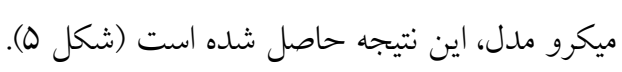

\section{نتايج و بحث}

نتايج بهدست آمده از انجـام آزمـايشهــاى ايسن تحقيـق، نشـان

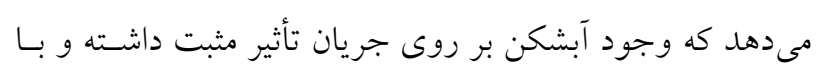

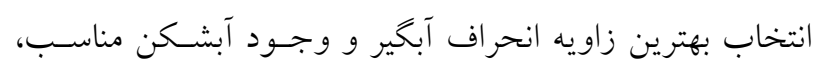
افزايش دبى ورودى به آبخير، حاصل مىشود.

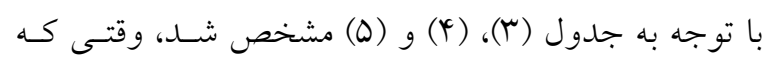

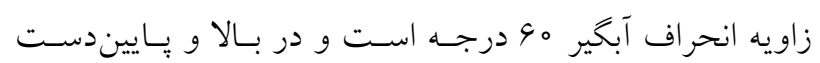

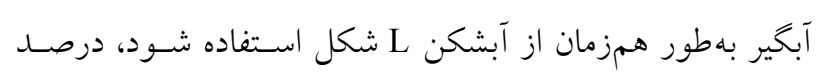

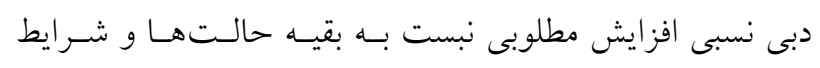

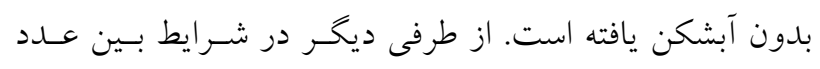

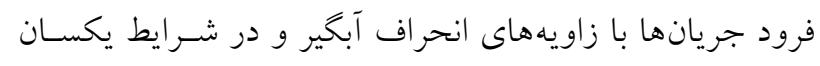

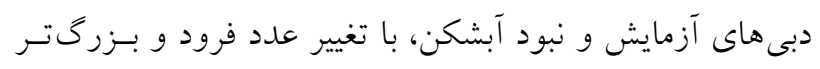

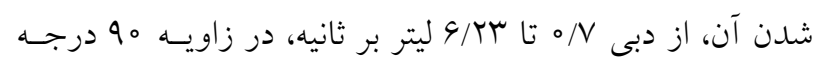

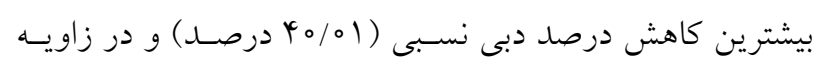

آزمايش بررسى شد كـهـ بـا ثبـت دادههــا و رســم نمودارهـا، در

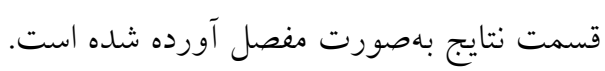

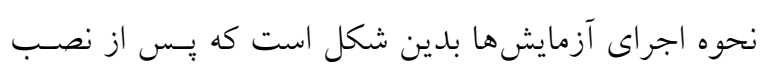

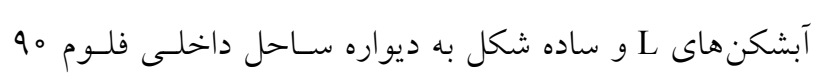

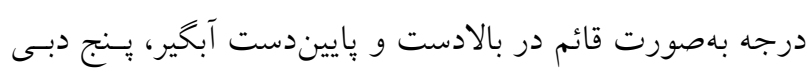

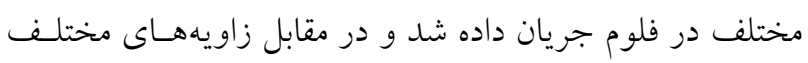

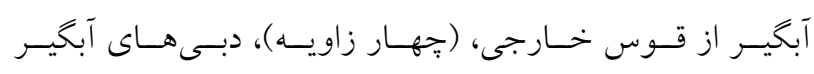

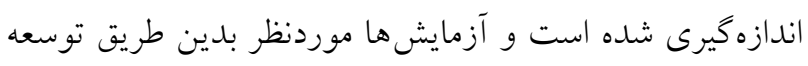

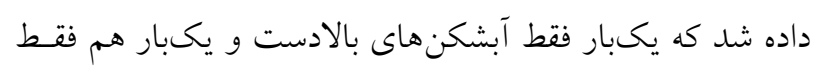

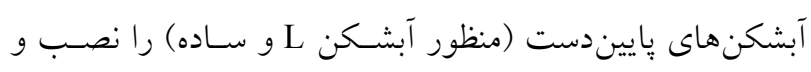

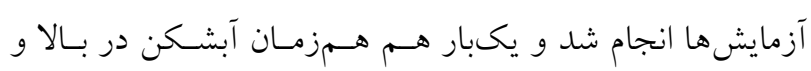

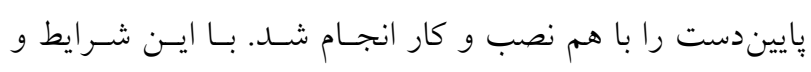

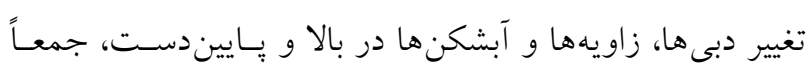

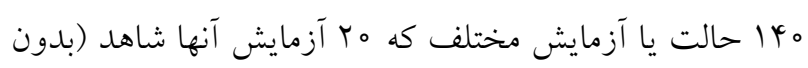

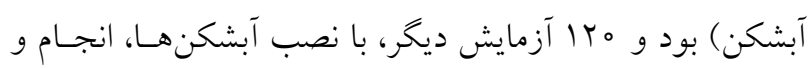

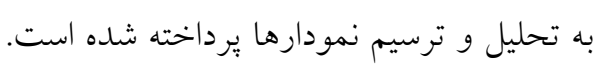

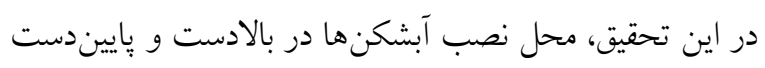

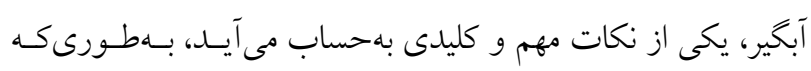

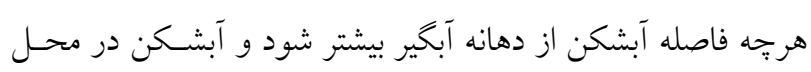

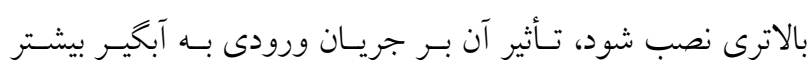

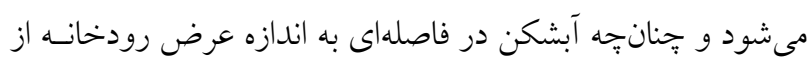

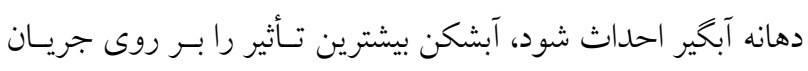


جدول r. محاسبات هيدروليكى آزمايشهاى مدل

\begin{tabular}{|c|c|c|c|c|c|c|c|c|c|c|c|c|}
\hline $\begin{array}{l}\hat{y} \\
\hat{y}\end{array}$ & 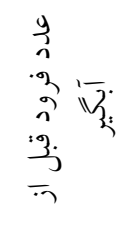 & 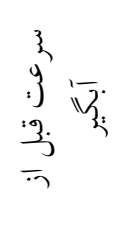 & 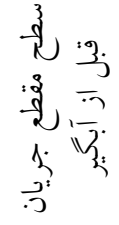 & $\begin{array}{l}\frac{y}{3} \\
3 \\
\frac{3}{1} \\
\frac{1}{12}\end{array}$ & 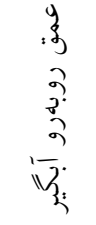 & 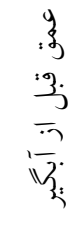 & $\begin{array}{l}\hat{j} \\
\overline{V_{j}}\end{array}$ & $\begin{array}{l}i j \\
i \\
\vdots \\
j\end{array}$ & $\begin{array}{l}\hat{y} \\
\hat{े} \\
\hat{y}\end{array}$ & $\begin{array}{l}3 \\
2 \\
3: \\
: 3 \\
: 3 . \\
: 3\end{array}$ & $\begin{array}{l}3 \\
0 \\
-3 \\
\cdot 3 \\
.3\end{array}$ & $\frac{\grave{2}}{\frac{3}{3}} \sqrt{\frac{1}{9}} \sqrt{2}$ \\
\hline$(\%)$ & بدون بعد & $(\mathrm{m} / \mathrm{s})$ & $\left(\mathrm{m}^{r}\right)$ & & $(\mathrm{cm})$ & & & $(\mathrm{L} / \mathrm{S})$ & & محل & شكل & درجه \\
\hline $94 / 0 V$ & 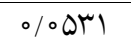 & O/OKYV & O/OY०Y & $r / 9$ & $r / \Delta$ & $\varphi / \% \Delta$ & $0 / 994$ & $\circ / 0{ }^{\prime} \wedge$ & $\circ / V$ & \multirow{20}{*}{$\begin{array}{l}3 \\
3 \\
.3 \\
.3 \\
.3 \\
.3\end{array}$} & \multirow{20}{*}{$\frac{3}{3}$} & $\mu_{0}$ \\
\hline $91 / 4 \pi$ & $\circ / \circ \Delta Y \circ$ & •/०rDI & $\circ / \circ Y_{\circ} \circ$ & $r / \Delta \Delta$ & $r / Y V$ & $\varphi / r$ &.$/ 94$ & $0 / 09$ & $\circ / V$ & & & id \\
\hline $90 / \mathrm{VI}$ & $\circ / 0 \Delta 9 \circ$ & ०/०rDq & .0190 & $\Gamma / \Delta$ & $r / r$ & $Y / r$ & $.19 \mathrm{~V}$ & \%/ r & $\circ / \mathrm{V}$ & & & 90 \\
\hline $90 / \mathrm{VI}$ & $0 / 090 Y$ & ०/०rVV & $0 / 01 \wedge 9$ & $r / \Delta$ & $r / \mathcal{T}$ & r & $.19 \mathrm{~V}$ & $0 / 0 r$ & $\circ / V$ & & & 90 \\
\hline $91 / 29$ &.$/ 090 \mathrm{~V}$ & $0 / 0491$ & ०/०rrq & $Y / T Y$ & $\varphi / \circ \mu$ & $0 / 19$ & $1 / 0 Y \Lambda$ & $0 / 09 r$ & $1 / 1 T$ & & & $\mu_{0}$ \\
\hline $91 / 99$ & $0 / 09 \wedge 9$ & ०/OYAT & אוץY0 & $4 / 1$ & $\varphi$ & 0 & $1 / 0 \mu$ & $0 / 09$ & $1 / 1 T$ & & & YQ \\
\hline$q 4 / T_{0}$ &.$/ 0 V 10$ & .0490 & O/OTYG & $r / v q$ & $r / \Lambda$ & $Y / M$ & $1 / \circ \Delta \Delta$ & $0 / 090$ & $1 / 1 T$ & & & 90 \\
\hline$q \pi / v D$ & $\circ / 0 V 11$ & .0 pqr & O/OTYV & $r / r$ & r & $4 / 9$ & $1 / 00$ & $\circ / \circ V$ & $1 / 1 T$ & & & 90 \\
\hline$\Lambda T / T V$ &.$/ \circ 94 \Delta$ & $\circ / \circ \wedge 1 \circ$ & O/OYYA & G/V & $9 / 4 \wedge$ & $V / D$ & T/MT & $\circ / 0$ & T/AY & & & $\mu_{0}$ \\
\hline$\Lambda F / 0 \psi^{r}$ & ०/lorq & ०/ノ^ & O/OMTV & $9 / 10$ & G/Or & $V / 04$ & $r / T V$ &.$/ 4 \Delta$ & T/AY & & & YQ \\
\hline$\Lambda Q / D T$ & $\circ / 1 \circ 19$ & $\circ / 0 \wedge 91$ & ००साद & 4 & $9 / 0 Y$ & G/AT & T/KY & $\circ / \mu$ & T/AT & & & 90 \\
\hline$\vee Q / \backslash \Lambda$ & $0 / 0949$ & $\circ / \circ \wedge \circ \circ$ & -/.ror & V & V & $V / 9$ & T/IT & $\circ / \mathrm{V}$ & T/AT & & & 90 \\
\hline $99 / \circ 0$ & $\circ / 1 / \mu 。$ & $\circ / 11 \circ \wedge$ & . \% YDQ & $9 / 0 r$ & N/VG & $9 / 1$ & $\mu / \mathcal{T} \Lambda$ & $1 / 09$ & $0 / 04$ & & & $\mu_{0}$ \\
\hline$V r / A l$ & ०/TYOO & - /lar & $.04 \mathrm{kV}$ & $\Lambda / \Delta \Lambda$ & $\Lambda / 4 \Lambda$ & $Q / 4 T$ & $r / V T$ & $1 / T r$ & $\Delta / \circ \psi^{4}$ & & & YQ \\
\hline$V Y / 90$ & $0 / 11 \wedge k$ & س & $0 / 0$ pty & $\Lambda / V \Lambda$ & N/Qr & $9 / 0$ & r/vG & $1 / Y \wedge$ & $Q / \circ \mathcal{C}^{4}$ & & & 90 \\
\hline $\mid\langle\wedge / \varphi|$ & $0 / 0994$ &.$/ 099 \mathrm{~V}$ & $0 / 00.4$ & $9 / 9$ & 10 & $10 / 9$ & T/MY & $T / 9$ & $Q / \circ \psi^{4}$ & & & 90 \\
\hline $99 / 00$ & ./TROI & o/IrVT & $0 / 0490$ & $9 / 09$ & $9 / 0 r$ & $10 / 9$ & س & $1 / 9$ & G/Kr & & & $\mu_{0}$ \\
\hline $99 / 91$ & -IYVA & $0 / 1 Y q 1$ & \% \%४NK & $9 / 01$ & $9 / 4$ & $10 / 4$ & $4 / T^{4}$ & $1 / A V$ & $9 / \pi r$ & & & Yo \\
\hline VN/AI & ०/IYVA & $0 / 1 Y q 1$ & ०/०YAN & $9 / 49$ & $9 / 4$ & $10 / 4$ & $4 / 91$ & $1 / T r$ & $9 / \pi r$ & & & 90 \\
\hline$\Delta \omega / \vee \circ$ & $\circ / 11 V \Delta$ & O/YYI & $\circ / \circ 010$ & 10 & $10 / \mu$ & 11 & $r / \mu V$ & T/VG & $9 / \pi r$ & & & 90 \\
\hline
\end{tabular}

افزايش مطلوبى نبست به بقيه حالتهـا و شـرايط بـدون آبشـكن

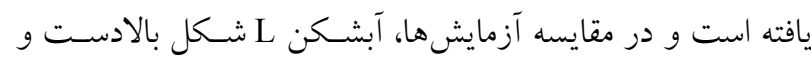

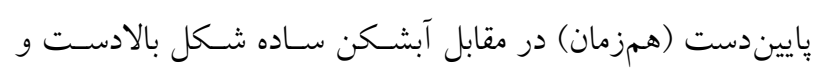
ياييندست (همزمان)، تأثير بهتـر و مثبتى داشـت و همجٍنسين در شرايط برابر ديخر حالتها، وجود آبشكن L شكل، بهعلت وجــود سبر L شكل، تأثير بيشترى روى خطوط جريان دارد.

\section{زاويه ثابت ه9 درجه}

در زاويه هو درجه، آبخير در راستاى جريـان وروددى بـهـ قـوس قـرار كرفته است، لذا جريان با كمترين اغتشاش وارد سر دهانه آبكير شــده
هو درجه، كمترين كاهش درصد دبى نسبى (19/9 درصد) بوده است، همجنين در شرايط يكسان دبسىهـاى آزمـايش و وجـود آبشكن L شـكل، در بالادست و وبـاييندسـت آبخيـر (بـهــور

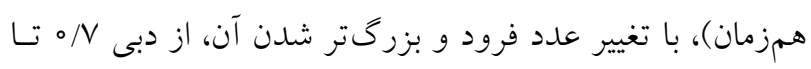

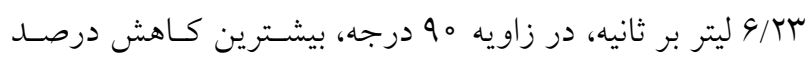
دبسى نسـبى (س/9/9 درصــد) و در زاويـهـ هو درجسه، كمتـرين كاهش درصد دبى نسبى (هه/ ا درصد) بوده است. با توجه به اشكال (9) تا (IT) مشخص شد وقتسى كـه زاويـه انحراف آبخير 09 درجه است و در بالا و ياييندست آبخير بهطور

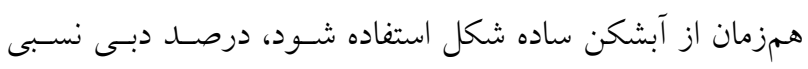


جدول f. محاسبات هيدروليكى مدل با همه دبىها و زاويهها در حالت بدون آبشكن

\begin{tabular}{|c|c|c|c|c|c|c|c|c|c|c|c|c|}
\hline $\begin{array}{l}\hat{i} \\
j \\
j\end{array}$ & 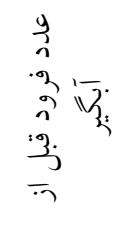 & 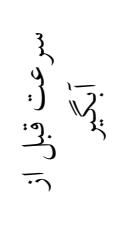 & 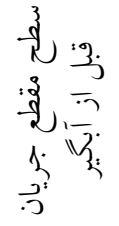 & $\begin{array}{l}9 \\
3 \\
3 \\
\frac{3}{15} \\
1 \overline{2}\end{array}$ & 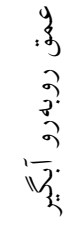 & 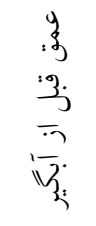 & $\frac{\hat{y}}{\bar{V}_{j}}$ & $\begin{array}{l}\hat{j} \\
\hat{j} \\
\hat{j}\end{array}$ & $\begin{array}{l}\hat{j} \\
\text { oे } \\
\hat{i}\end{array}$ & $\begin{array}{l}3 \\
: 2 \\
: 3 \\
1 \frac{3}{.3} \\
\frac{3}{3}\end{array}$ & $\begin{array}{l}3 \\
\frac{3}{3} \\
\frac{3}{3} \\
\frac{3}{3}\end{array}$ & $\frac{7}{3}$ \\
\hline$(\%)$ & بدون بعد & $(\mathrm{m} / \mathrm{s})$ & $\left(\mathrm{m}^{r}\right)$ & & $(\mathrm{cm})$ & & & $(\mathrm{L} / \mathrm{S})$ & & محل & شكل & درجه \\
\hline $94 / 0 V$ & $\circ / \circ \Delta M^{\prime}$ & O/OYKV & $\circ / \circ Y \circ Y$ & $r / 9$ & $\Gamma / Q$ & $\varphi / \mu \Delta$ & $0 / 994$ & \%०YN & $\circ / V$ & \multirow{20}{*}{$\begin{array}{l}3 \\
3 \\
.5 \\
\frac{1}{.3} \\
.3\end{array}$} & \multirow{20}{*}{$\frac{3}{3}$} & \multirow{5}{*}{$\mu_{0}$} \\
\hline $91 / 29$ &.$/ 090 \mathrm{~V}$ & $0 / 0491$ & ०/० Trq & $Y / T Y$ & $r / \circ r$ & $0 / 19$ & I/OYA &.$/ 09 r$ & $1 / 1 r$ & & & \\
\hline$\Lambda T / T V$ &.$/ 0 q 40$ & $\circ / \circ \wedge 1 \circ$ & ०/OMYA & $9 / V$ & $9 / 4 \wedge$ & $\mathrm{V} / \mathrm{Q}$ & r/Mr & $\circ / 0$ & T/AY & & & \\
\hline $99 / 00$ & $\circ / 11 \% \circ$ & $\circ / 11 \circ \wedge$ & ० & $9 / 0 r$ & $\Lambda / V q$ & $9 / 1$ & $r / \mu \wedge$ & $1 / 09$ & $Q / \circ \psi^{\psi}$ & & & \\
\hline $99 / 0$ & ०/TQU & o/rVr & $0 / 0490$ & $9 / 09$ & $9 / \Delta r$ & $10 / 00$ & r/4 & $1 / 9$ & G/Tr & & & \\
\hline $91 / 4 r$ & $\circ / \circ \Delta Y \circ$ & ०/\% rDI & ०/०Y०० & $\Gamma / \Delta Q$ & $r / \mathcal{Q ⿻}$ & $\varphi / \mu$ & $0 / 94$ & $0 / 09$ & $\circ / V$ & & & \multirow{5}{*}{ YQ } \\
\hline $91 / 99$ & $0 / 0419$ & \%०YAr & ०/०YMY & $p / 1$ & r & 0 & $1 / \circ r$ & $0 / 09$ & $1 / 1 r$ & & & \\
\hline$\Lambda Y / 0 Y^{x}$ & $\circ / 1 \circ r_{q}$ & ०/०^צr & ०/OYTV & $9 / \pi \Delta$ & $9 / 0 Y$ & $V / 04$ & $r / r V$ & $\circ / 4 \Delta$ & T/AY & & & \\
\hline$V \pi / \Lambda)$ & O/YTOO & - /llar & $0 / 0 \mu r v$ & $\Lambda / \Delta \Lambda$ & $\Lambda / \uparrow \Lambda$ & $q / 4 Y$ & rNY & $1 / \pi r$ & $\Delta / \circ \varphi^{r}$ & & & \\
\hline $99 / 91$ & -/ITVA & $0 / 1 r q \mid$ & \%orin & $9 / 01$ & $9 / 4$ & $10 / 4$ & $4 / M_{4}$ & I/AV & $9 / \pi r$ & & & \\
\hline $9 \Delta / V I$ & ००ఎ९० & ०/०MQq &.$/ 0190$ & $r / \phi$ & $r / r$ & $Y / r$ &.$/ 9 \mathrm{~V}$ & $\circ / 0 \mu$ & $\circ / V$ & & & \multirow{5}{*}{90} \\
\hline$q r / r$ &.$/ 0 V 10$ & .10490 & O/OTYG & $r / v q$ & $r / \Lambda$ & $Y / \Lambda \Lambda$ & $1 / \circ \Delta \Delta$ & .090 & $1 / 1 Y$ & & & \\
\hline$\Lambda G / O T$ & $\circ / 1019$ & $\circ / 0 \wedge 91$ & .०Mाद & 9 & $9 / 04$ & G/Ar & T/FY & $\circ / \mu \wedge$ & T/AY & & & \\
\hline$V \Psi / 9$ & $0 / 11 \wedge 4$ & $0 / 11 k$ r & $0 / 0 y \forall \mid$ & $\Lambda / V \Lambda$ & N/Qr & $9 / 0$ & r/vG & $1 / Y \wedge$ & $Q / \circ \psi^{\psi}$ & & & \\
\hline VN/AI & ०/TVA & $0 / 1 Y 91$ & ०/0YNR & $q / 4 q$ & $9 / 4$ & $10 / 4$ & $4 / 91$ & I/rr & G/Tr & & & \\
\hline $90 / \mathrm{VI}$ & $0 / 090 Y$ & ०/०HVV & $0 / 01 \wedge 9$ & $\Gamma / \phi$ & $\mu / \mu$ & r & $0 / 9 \mathrm{~V}$ & $\circ / 0 \mu$ & $\circ / V$ & & & \multirow{5}{*}{$9 \circ$} \\
\hline$q r / v Q$ &.$/ 0 V 11$ & .0 pqr & \%OYTV & $\varphi / r$ & $r$ & $4 / 9$ & $1 / \circ 0$ & $\circ / \circ \mathrm{V}$ & $1 / 1 T$ & & & \\
\hline$V Q / \backslash \wedge$ & $0 / 0949$ & $\circ / \circ \wedge \circ \circ$ & •/०rar & v & V & $V / 9$ & r/T & $\circ / \mathrm{V}$ & T/AY & & & \\
\hline $\mid\langle\wedge / 4|$ & .10994 & $.099 \mathrm{~V}$ & $\circ / \circ 0 \circ 9$ & $9 / 9$ & 10 & $10 / 9$ & r/AY & $r / 9$ & $0 / 0 \psi^{r}$ & & & \\
\hline$\Delta \Delta / \vee$ & - /IVD & O/YKYI & $\circ / 0010$ & 10 & $10 / \pi$ & 11 & $r / \mu V$ & T/VG & $9 / \pi \mu$ & & & \\
\hline
\end{tabular}

بايستى جرخش تندى بكند. در اين زاويه، آبخير عمود بر قـوس

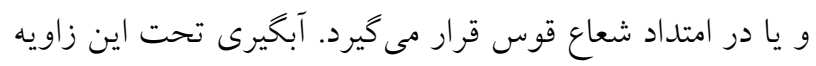

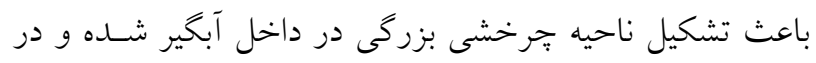

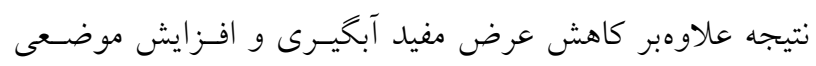

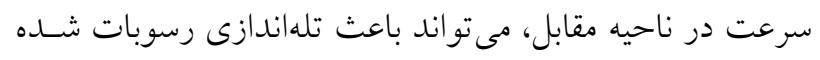
و موجب ايجاد اختلال اساسى در سيستم آبخير شود.

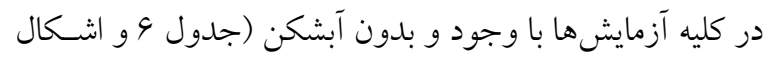

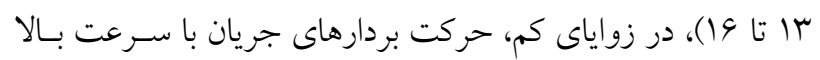

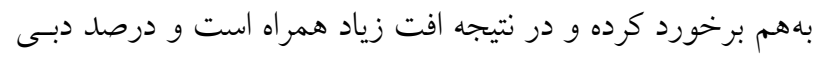

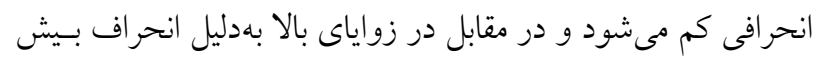

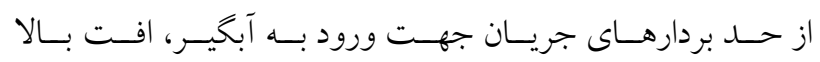

و الكَوى جريان ورودى به سر دهانه آبخير بـهدليـل هـمراسـتا بـودن

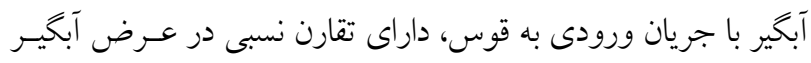

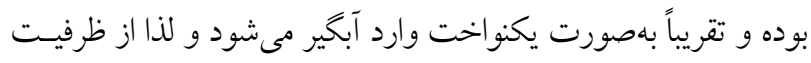

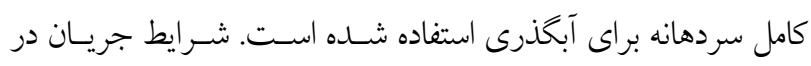
سر دهانه نشان مىدهد كـه در انحـر اف دبسى، جريـان ثانويسه در لبـهـ

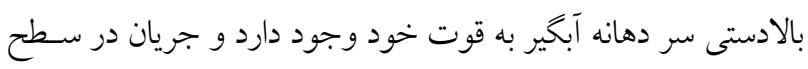
به سمت قوس خارجى و در كف بـه سـمت قـوس داخلمى متمايـل

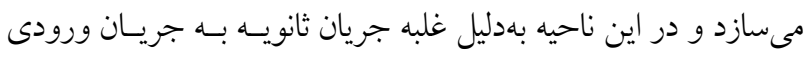
به آبخير كه معكوس يكديخر هستند و دبى آبخير بيشتر مىشود.

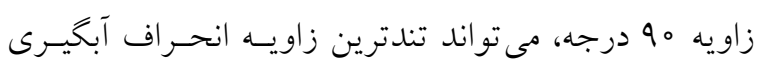
باشد. در اين زاويـه، جريـان بـراى ورود بـهـ سـر دهانـه آبخيـر 
جدول ه. محاسبات هيدروليكى مدل با همه دبىها و زاويهها با آبشكن L بالا و پايين دست

\begin{tabular}{|c|c|c|c|c|c|c|c|c|c|c|c|c|}
\hline$\hat{y}_{j}$ & 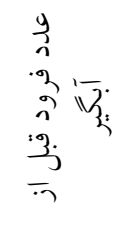 & $\begin{array}{l}3 \\
y^{3} \\
: \sqrt{2} \\
\text { :3. } \\
=\end{array}$ & 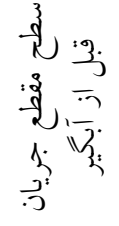 & 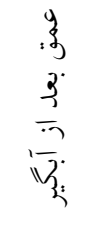 & 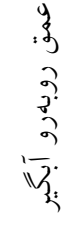 & 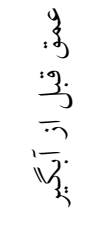 & $\begin{array}{l}\hat{i} \\
\overline{\mathbb{Z}_{i}}\end{array}$ & $\begin{array}{l}3 \\
\dot{y} \\
\hat{j} \\
\hat{j}\end{array}$ & $\begin{array}{l}\hat{y} \\
\text { के } \\
\hat{y}\end{array}$ & $\begin{array}{l}3 \\
: 2 \\
: 3 \\
1 \frac{1}{3} \\
\frac{3}{3}\end{array}$ & $\begin{array}{l}3 \\
\frac{3}{3} \\
\frac{3}{3} \\
\frac{3}{3}\end{array}$ & $\ddot{\vec{s}}$ \\
\hline$(\%)$ & بلدون بعد & $(\mathrm{m} / \mathrm{s})$ & $\left(\mathrm{m}^{r}\right)$ & & $(\mathrm{cm})$ & & & $(\mathrm{L} / \mathrm{S})$ & & محل & شكل & درجه \\
\hline $90 / 0 \circ$ & ०/०DY० & O/OMYK & $\circ / \circ Y \circ Q$ & $r / \Delta$ & $\mu / \mu$ & $r / 41$ & .1990 & $\circ / \circ \mu_{\Delta}$ & $\circ / V$ & \multirow{5}{*}{$\begin{array}{l}3 \\
3 \\
9 \\
3 \\
3 \\
3 \\
3 \\
3 \\
3\end{array}$} & \multirow{5}{*}{ L } & \multirow{5}{*}{$\mu_{0}$} \\
\hline $94 / 94$ & $0109 \mathrm{VV}$ & $0 / 0 Y V V$ & - / & $4 / r q$ & $\varphi / \circ \Delta$ & $0 / 09$ & $1 / 09$ & $0 / 09$ & $1 / 1 T$ & & & \\
\hline$\Lambda \varphi / \Delta r$ &.$/ 0 q 40$ & $\circ / \circ \wedge 1 \circ$ & ०/०YYA & $9 / 01$ & $9 / 4 \wedge$ & $V / Q$ & $r / 4 Y$ & $\circ / \aleph \wedge$ & T/AY & & & \\
\hline$V \Psi / \Lambda l$ & $\circ / 1 \circ 9 V$ & $\circ / \mid \circ \wedge \varphi$ & olotak & $1 / 90$ & 9 & 10 & $r / N T$ & $1 / \pi r$ & $Q / 0 Y$ & & & \\
\hline$V G / N^{T}$ & O/KY。 & -/TOI & .0491 & $9 / V V$ & $9 / 90$ & $10 / N$ & $Y / V \Lambda$ & $1 / 40$ & $9 / \pi r$ & & & \\
\hline $94 / 49$ & ०/०DY० & O/OMYK & $\circ / \circ Y \circ Q$ & $r / 01$ & $r / \omega$ & $\varphi / 41$ & $0 / 94$ & $0 / 04$ & $\circ / V$ & \multirow{5}{*}{$\begin{array}{l}7 \\
9 \\
3 \\
3 \\
3 \\
3 \\
3 \\
3 \\
3\end{array}$} & \multirow{5}{*}{ L } & \multirow{5}{*}{ id } \\
\hline $9 Q / D F$ & 010919 & \% OYAr & ס & $\varphi / \circ \Delta$ & $\varphi$ & 0 & $1 / 0 V$ & $\circ / 00$ & $1 / 1 T$ & & & \\
\hline$q \circ / v \wedge$ &.$/ 0994$ & $\circ / \circ \wedge \mu \wedge$ & צח & $9 / \pi 9$ & $4 / 00$ & $V / T Q$ & $r / \Delta Q$ & $0 / Y 4$ & T/AY & & & \\
\hline$V Q / ৭ ৭$ & $\circ / 1 \mathrm{VQ}$ & $0 / 11 T V$ & o/opkr & $N / D G$ & $\Lambda / 4 Q$ & $9 / 00$ & r/Ar & $|/ r|$ & $Q / 0 Y$ & & & \\
\hline VN/AI & O/ KG. & ०/ TVVq & $\circ / 0 Y \wedge \vee$ & $Q / D Y$ & $9 / 0 V$ & $10 / 0$ & $4 / 91$ & $1 / \pi T$ & $9 / \pi$ & & & \\
\hline $99 / 44$ & ००09० & ०/PQQ &.$/ 0190$ & $r / 4$ & $r / r$ & $Y / r$ & $0 / 9 V D$ & ०/०TQ & $\circ / V$ & \multirow{5}{*}{$\begin{array}{l}3 \\
2 \\
9 \\
3 \\
3 \\
3 \\
3 \\
3 \\
3 \\
3\end{array}$} & \multirow{5}{*}{$\mathrm{L}$} & \multirow{5}{*}{90} \\
\hline $99 / 11$ & $\circ / \circ V T V$ & $\circ / \circ \Delta \circ \Delta$ & O/OYTY & $\Gamma / \wedge \Delta$ & $r / \Lambda Y$ & Y/VA & $1 / \circ \wedge \Delta$ & ס & $1 / 1 T$ & & & \\
\hline Q०/VA & $\circ / / \circ Y \wedge$ & $\circ / \circ \wedge \Delta V$ & ०/०rrq & $9 / Y Y$ & 9 & $V / 09$ & r/DS & $0 / 49$ & T/AY & & & \\
\hline $10 / 19$ & $\circ / 11 \mathrm{~V}$ & $0 / 11$ MY & oryto & $\Lambda / V$ & $\Lambda / V$ & $9 / 0 \wedge$ & $y / 04$ & 1 & $0 / 0 Y$ & & & \\
\hline$\Lambda 1 / \Lambda$ & $0 / 1 Y 99$ & $\circ / T Y \wedge \Delta$ & $\circ / \circ \uparrow \wedge \Delta$ & $9 / 49$ & $9 / 4 \wedge$ & $10 / 40$ & $\Delta / \circ V$ & $1 / 19$ & $9 / \pi$ & & & \\
\hline $99 / 44$ & ००09० & ०/०QDQ & .0190 & $\mu / \mu$ & $\mu / \mu$ & $\varphi / r$ &.$/ 9 V D$ &.$/ 0 T Q$ & $\circ / V$ & \multirow{5}{*}{$\begin{array}{l}3 \\
2 \\
9 \\
3 \\
3 \vdots \\
3 \\
3 \\
3 \\
3\end{array}$} & \multirow{5}{*}{$\mathrm{L}$} & \multirow{5}{*}{90} \\
\hline $99 / 44$ & 010919 & ०/०YAN & אTYOT & $r / 90$ & y & 0 & $1 / \circ \wedge$ & $0 \%$ & $1 / 1 T$ & & & \\
\hline $1 r / 99$ & $\circ / \circ \wedge \Delta \wedge$ & ०/०VG。 & o/orvi & $9 / 1$ & v & $\wedge$ & T/RG & $0 / 49$ & T/AY & & & \\
\hline $9 Y / 90$ & $\circ / 1 \circ \mu r$ & ollopt & ०/OYAN & $9 / 4$ & $9 / 9$ & $10 / 4$ & $r / I V$ & I/AV & $Q / 0 Y$ & & & \\
\hline $99 / 0 \circ$ & $0 / 1099$ &.$/ 119 \wedge$ & $\circ / \circ \Delta \mu Y$ & $10 / 11$ & $10 / 0$ & $11 / 0$ & r/T & $1 / 9$ & $9 / \pi$ & & & \\
\hline
\end{tabular}

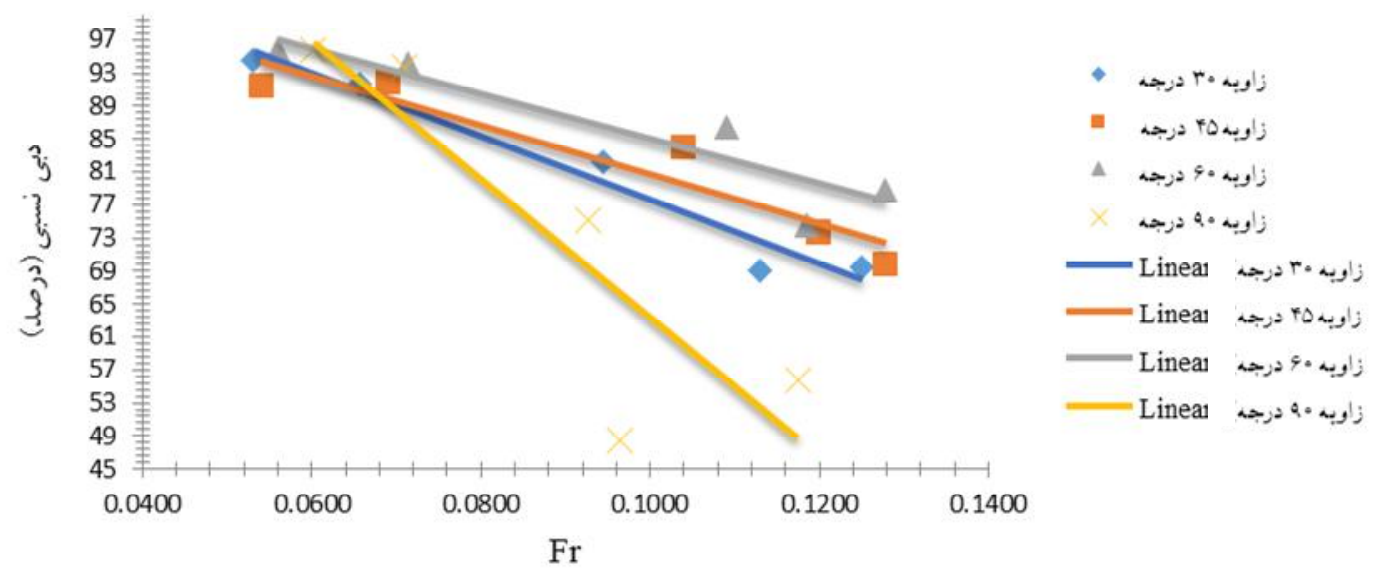

شكل و. نمودار تغييرات دبى نسبى - عدد فرود با همه دبىها و زاويهها در حالت بدون آبشكن 


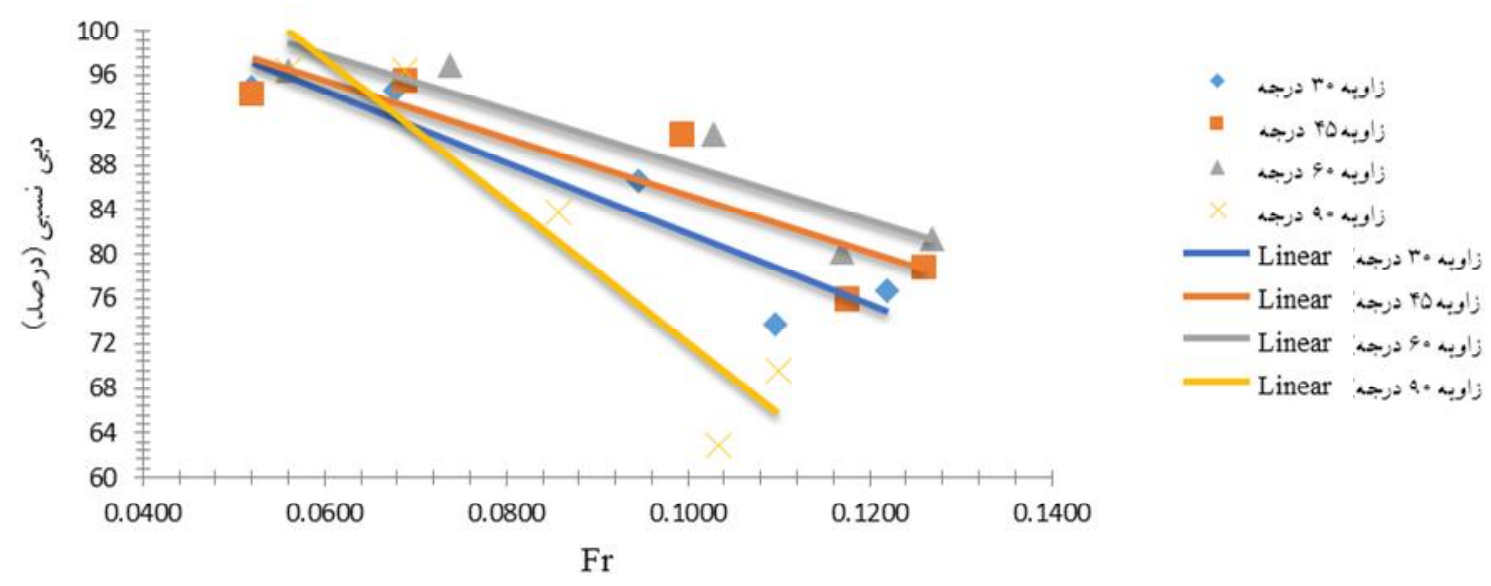

شكل V. نمودار تغييرات دبى نسبى - عدد فرود با همه دبىها و زاويهها با آبشكن L بالا و پِاييندست

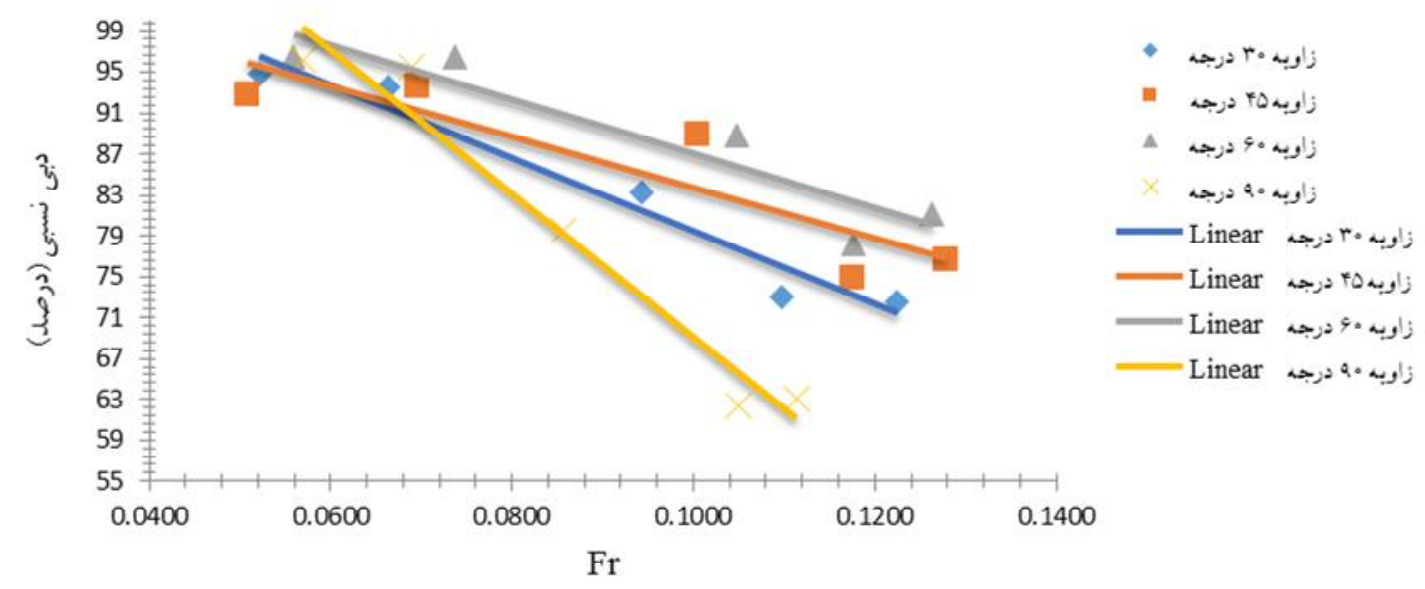

شكل ^. نمودار تغييرات دبى نسبى - عدد فرود با همه دبىها و زاويهها با آبشكن L بالادست
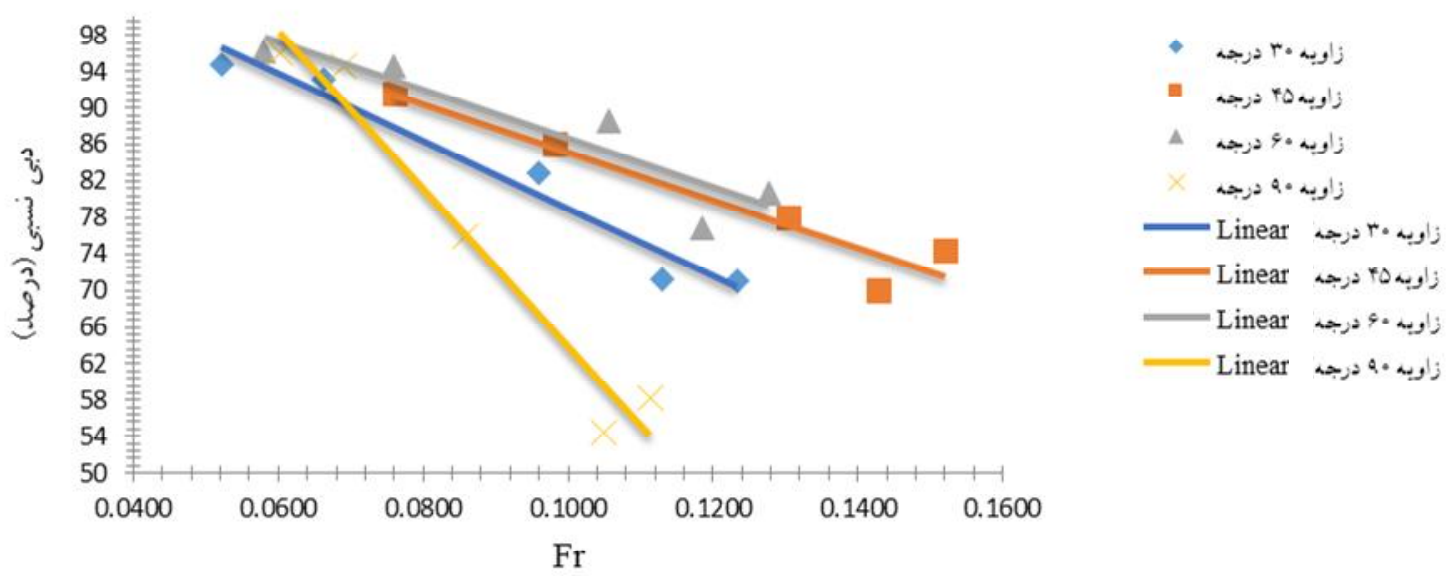

شكله. نمودار تغييرات دبى نسبى - عدد فرود با همه دبىهاو زاويهها با آبشكن L پاييندست 


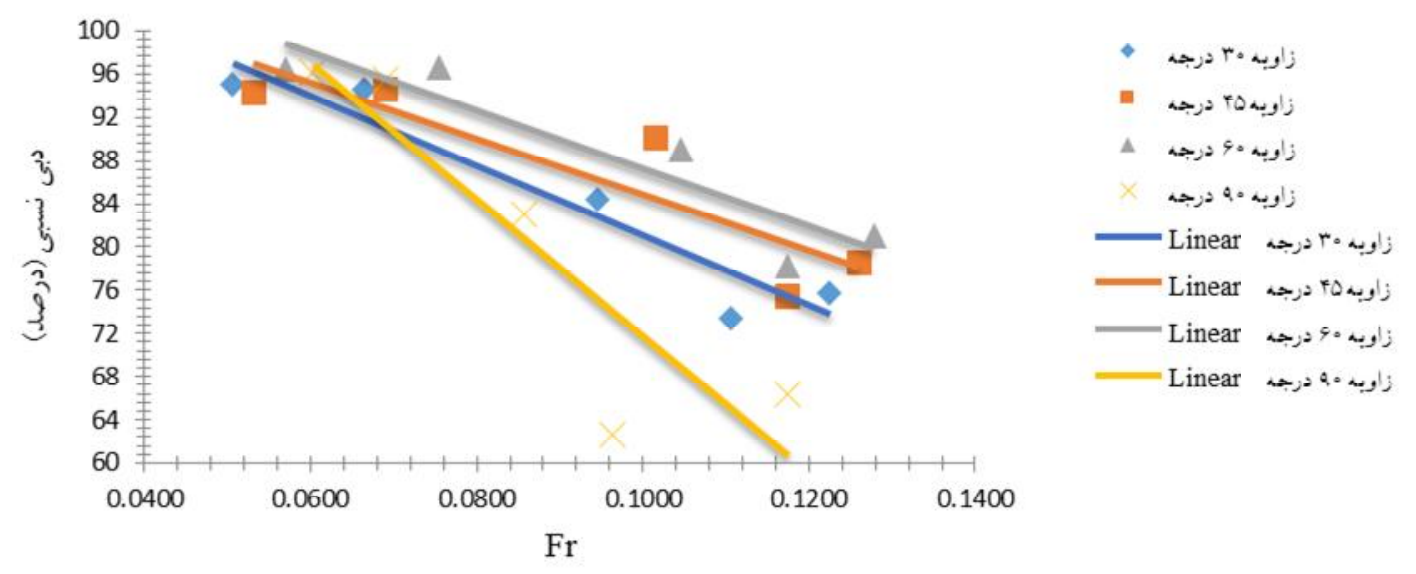

شكل ه ا. نمودار تغييرات دبى نسبى - عدد فرود با همه دبى هاو زاويهها با آبشكن ساده بالا و پِاييندست

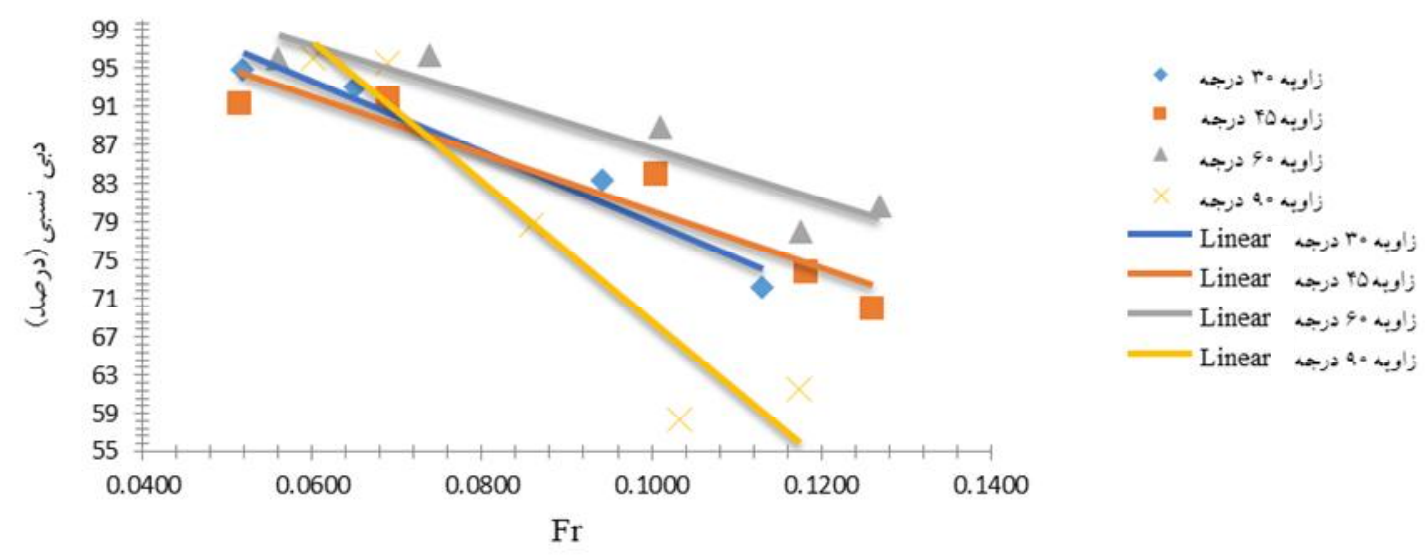

شكل ال. نمودار تغييرات دبى نسبى - عدد فرود با همه دبىها و زاويهها با آبشكن ساده بالادست

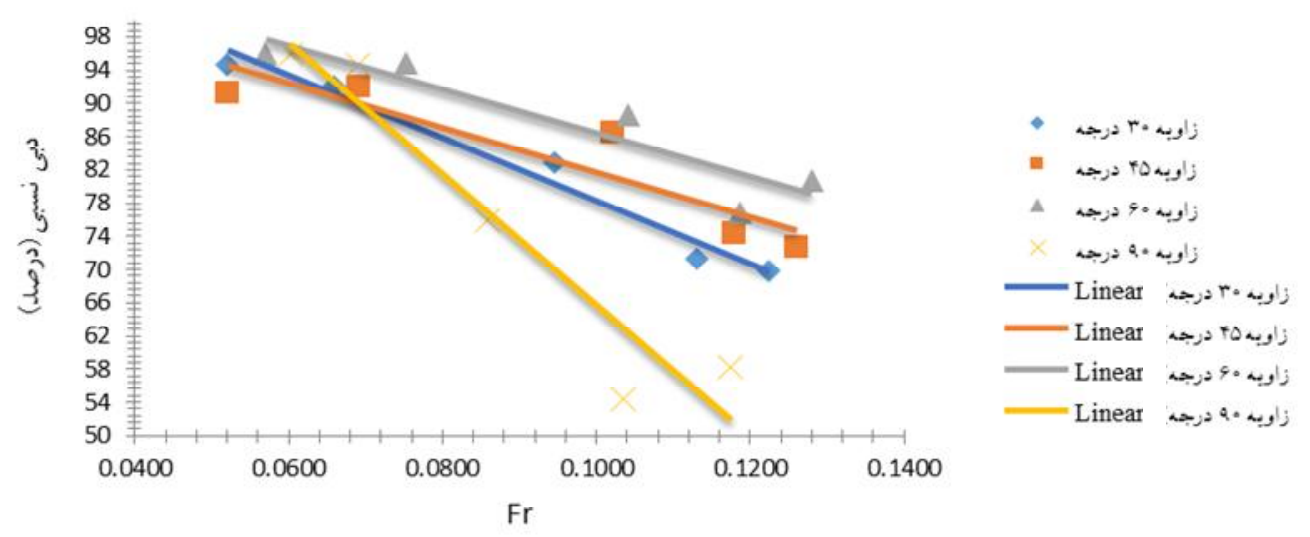

شكل r ا. نمودار تغييرات دبى نسبى - عدد فرود با همه دبىها و زاويهها با آبشكن ساده ياييندست 
جدول 9. محاسبات هيدروليكى مدل با همه دبىها و حالتهاى آبشكنها در زاويه ه9 درجه

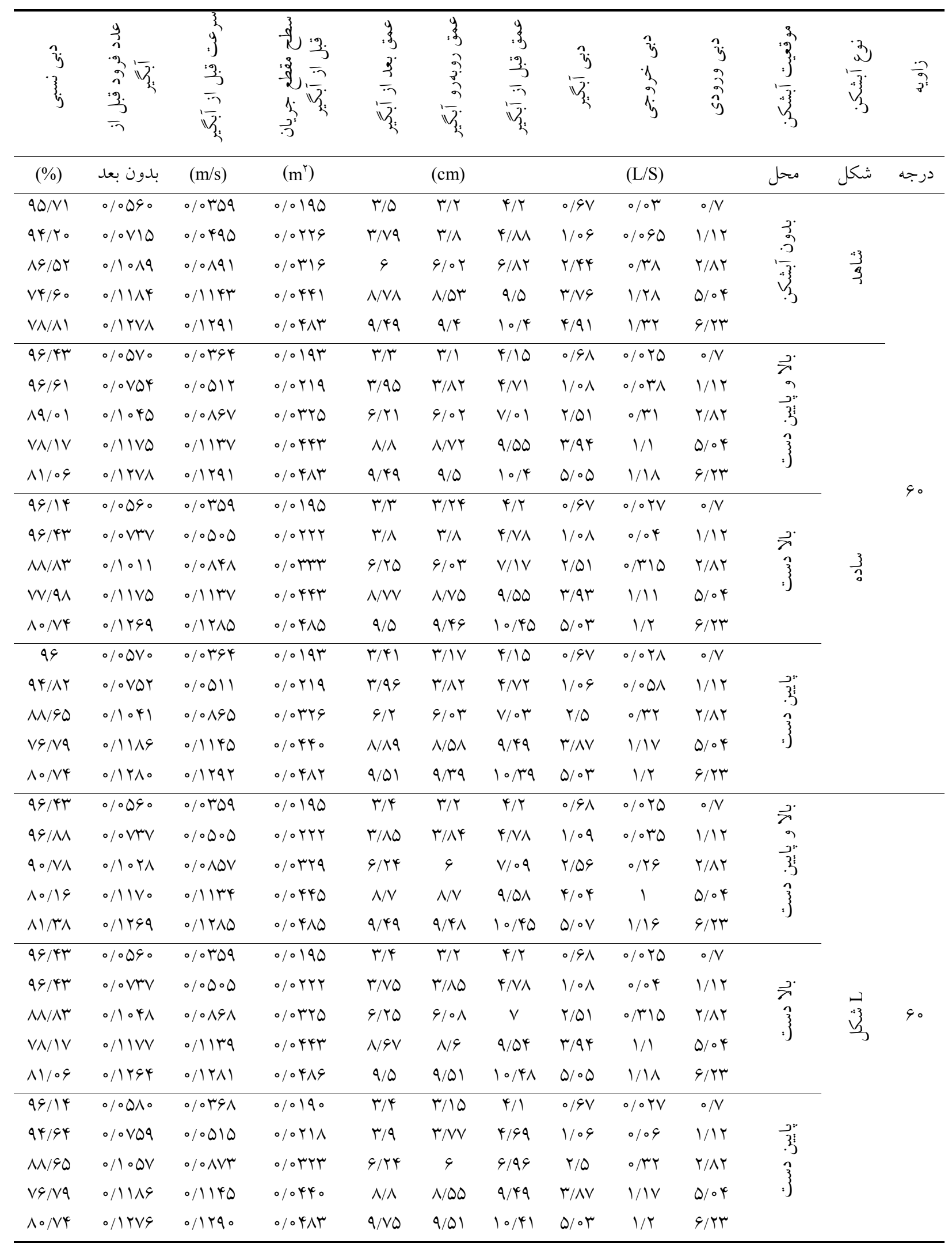




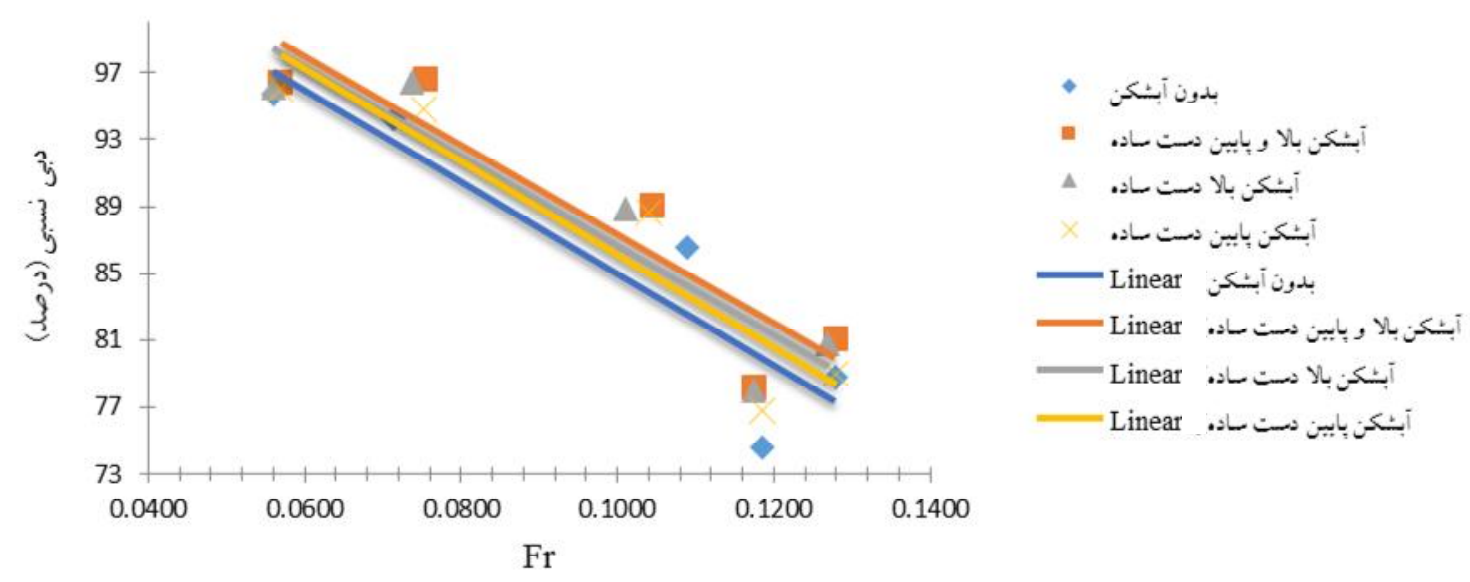

شكل با. نمودار تغييرات دبى نسبى - عدد فرود با وجود حالتهاى مختلف آبشكن ساده با زاويه ه4 درجه

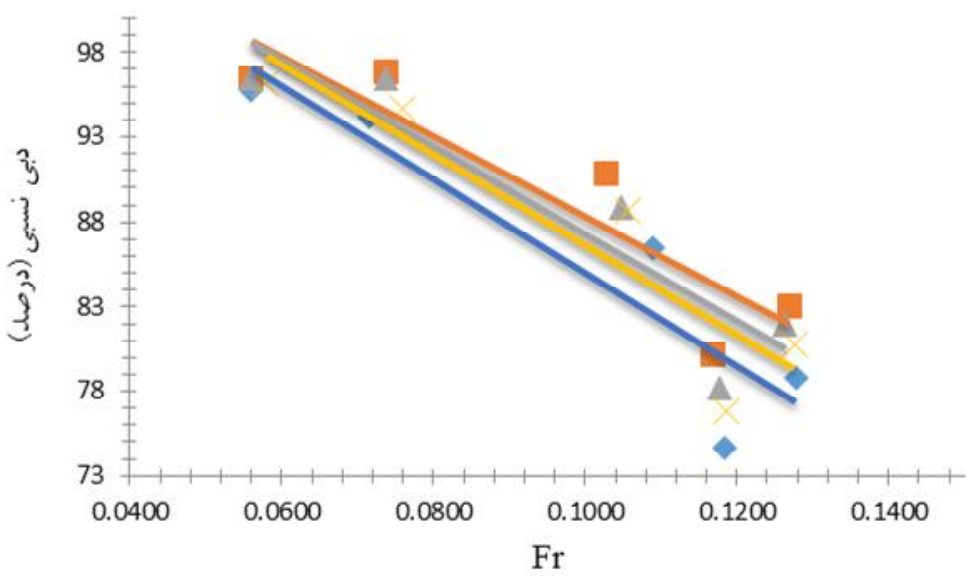

بدون أبـكن.

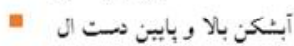

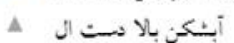

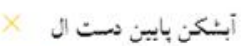

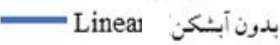

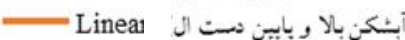

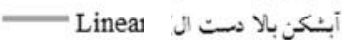

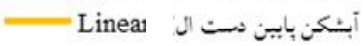

شكل ff ا. نمودار تغييرات دبى نسبى - عدد فرود با وجود حالتهاى مختلف آبشكن L با زاويه ه9 درجه

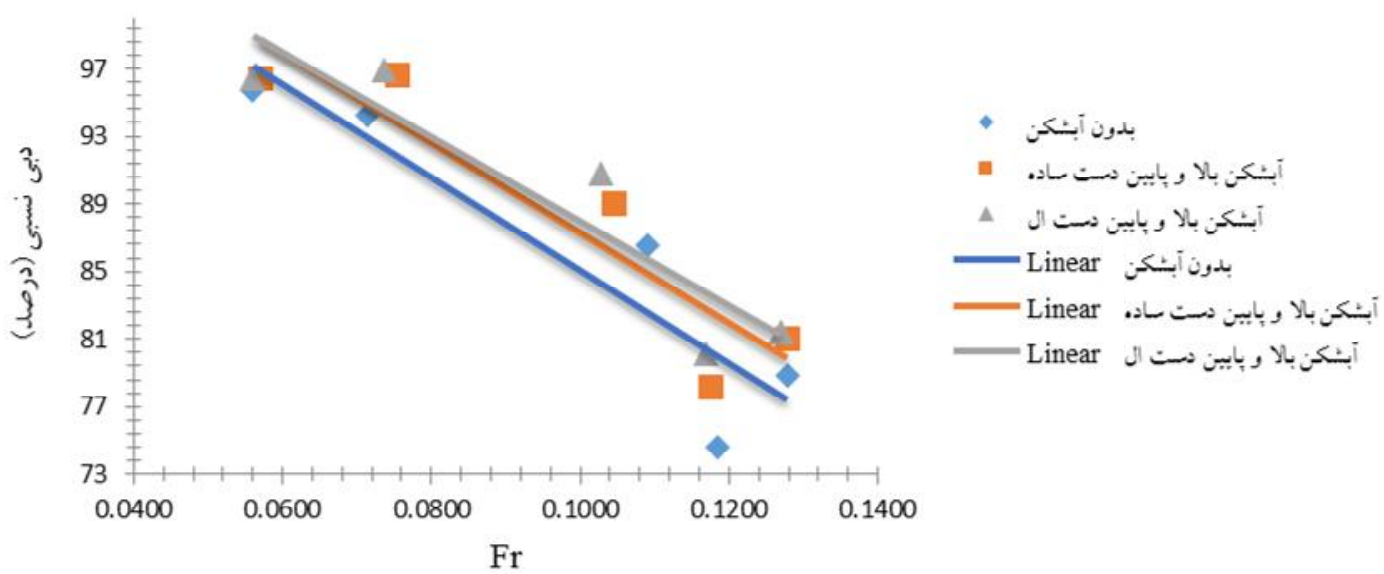

شكل ها. نمودار تغييرات دبى نسبى - عدد فرود با آبشكن L و ساده در بالا و پِاييندست با زاويه ه9 درجه 


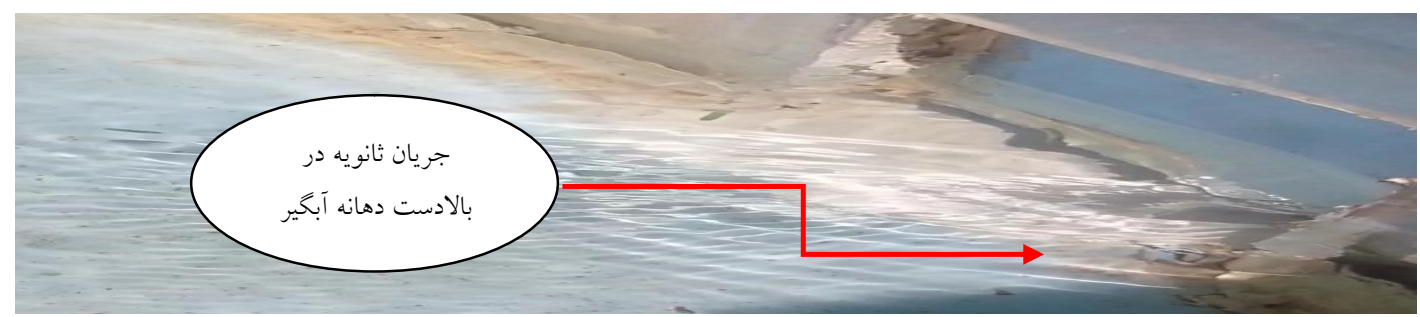

شكل 19. جريان ثانويه در بالادست آبخير جانبى

خطوط جريان و انحراف به طرف آبخير، بيشتر از آبشكن ساده است.

\section{بهترين و نامناسب ترين زاويه انحراف آبخير}

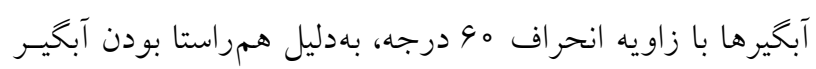

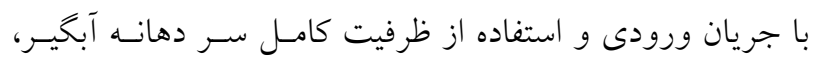
بيشترين دبى انحر افى را دارا هستند و براساس مطالعات بيشسين

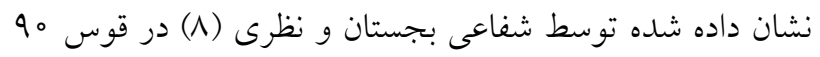

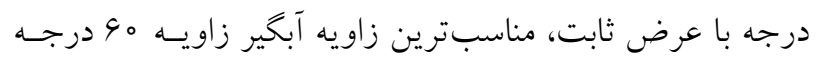

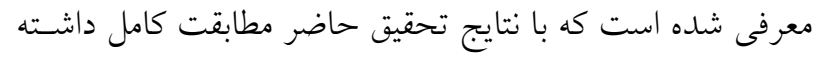

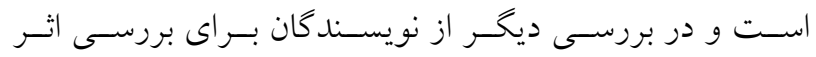

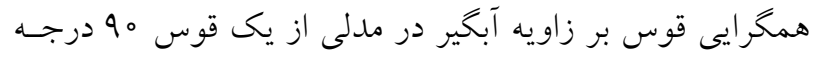

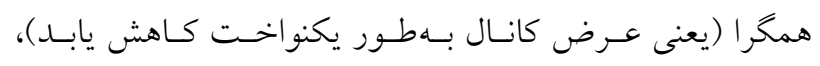

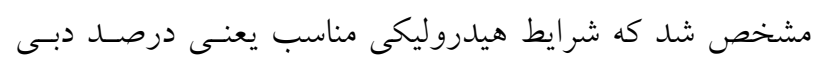

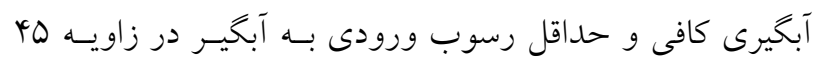

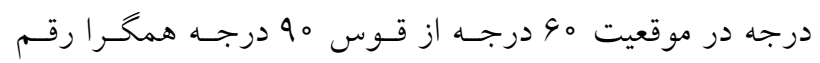

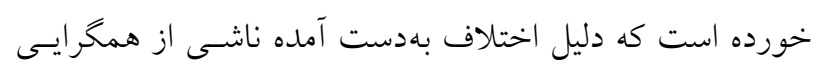
قوس در اين مطالعه بود زيرا الكوى جريان در قوس هاى همخرا

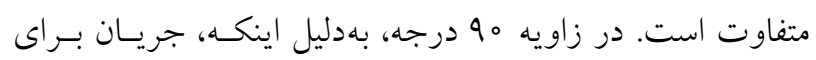

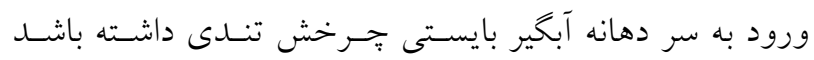
تندترين و نامناسبترين زاويه انحراف آبخيرى است.

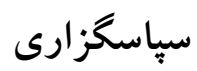

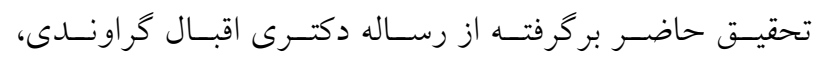

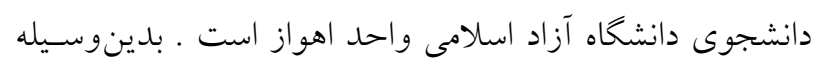

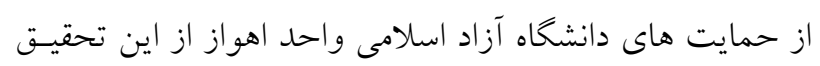

$$
\text { تشكر و قدردانى مىشود . مائ دانئاه }
$$

رفته و در نتيجه دبى كاهش مى يابد، بنابراين در زاويسه م9 درجـهـ

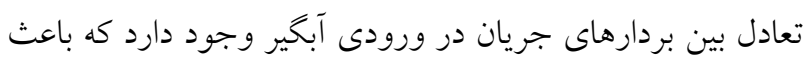

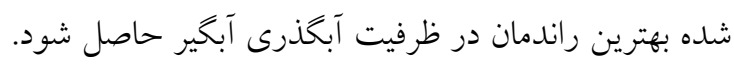

\section{نتيجه گيرى}

تأثير آبشكن ساده شكل بر دبى انحرافى آبخير

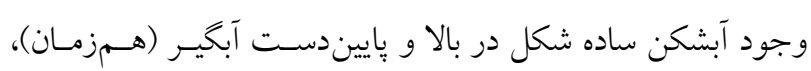

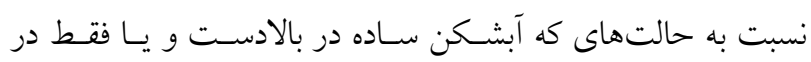

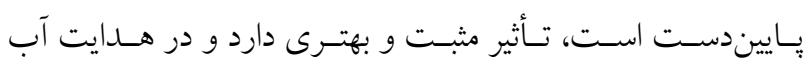

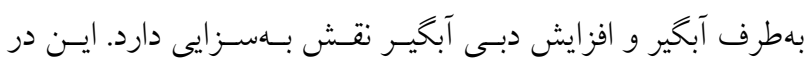

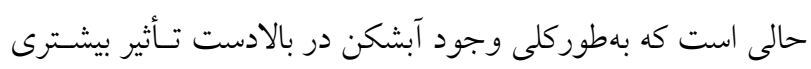

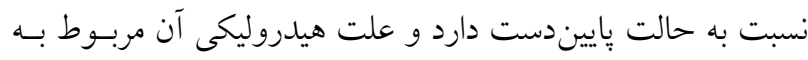
بالا آوردن سطح آب و تغيير جهت جريان به بـ آبخير است.

\section{تأثير آبشكن L شكل بر دبى انحرافى آبخير} وجود آبشكن L شكل در بالادست و باييندست آبخير (هـمزمـان)،

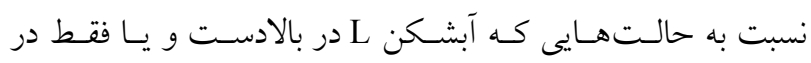

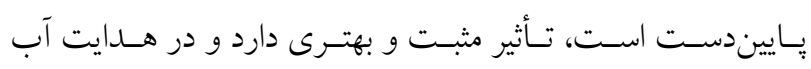

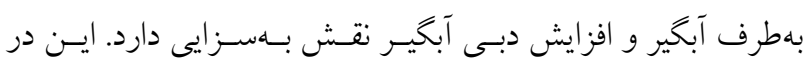

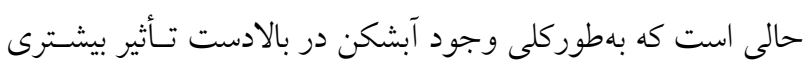

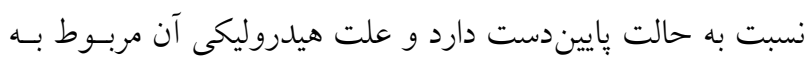

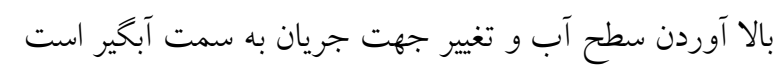

\section{مقايسه دو نوع آبشكن L و ساده شكل}

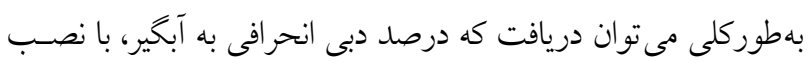

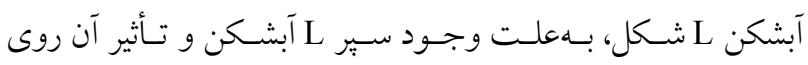




$$
\begin{aligned}
& \text { منابع مورد استفاده }
\end{aligned}
$$

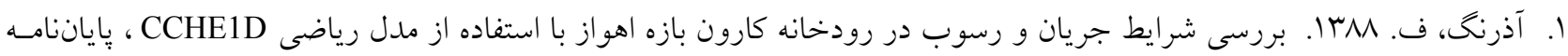

$$
\begin{aligned}
& \text { كارشناسى ارشد، دانشخاه آزاد اسلامى، واحد علوم و تحقيقات، خوزستان. } \\
& \text { r. اسماعيل نزاد، م. اليَا. بررسى آزمايشگاهى هيدروليك جريان ورودى به آبكيرهاى سد انحرافى حميديه با استفاده از ميكرومــل، } \\
& \text { باياننامه كارشناسى ارشد، دانشخاه شهيد جّمران، اهواز. }
\end{aligned}
$$

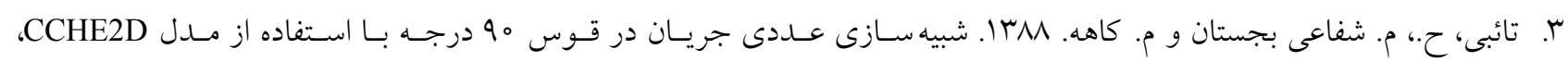

$$
\begin{aligned}
& \text { هشتمين سمينار بين المللى مهندسى رودخانه، دانشخاه شهيد جهمران، اهواز. }
\end{aligned}
$$

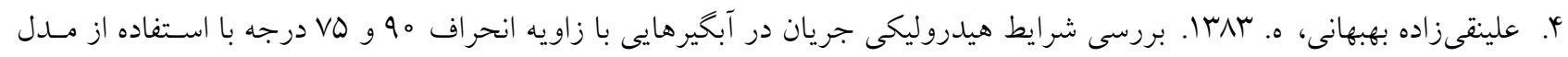

$$
\begin{aligned}
& \text { فيزيكى، باياننامه كارشناسى ارشد، دانشخاه شهيد جِمران، اهواز. }
\end{aligned}
$$

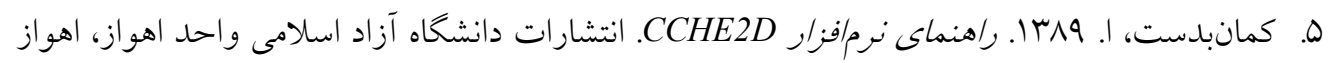

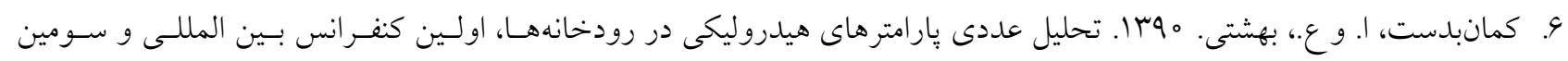

$$
\begin{aligned}
& \text { كنفر انس ملى سد و نيرو گاههاى برق آبى، تهران. }
\end{aligned}
$$

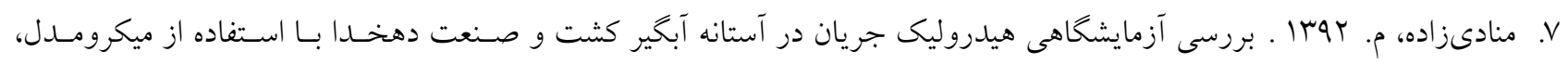

$$
\begin{aligned}
& \text { ياياننامه كارشناسى ارشد، دانشخاه آزاد شوشتر، خوزستان. }
\end{aligned}
$$

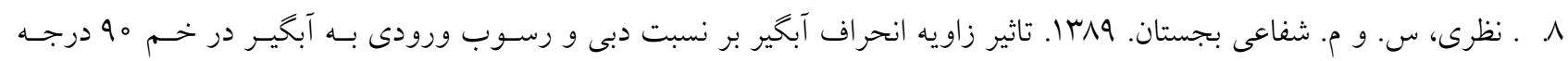

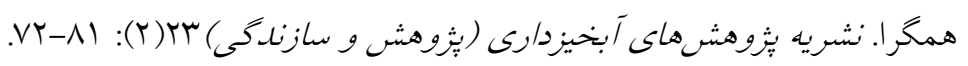

9. Barkdoll, B. D., R. Ettemaand A. J. Odgaard. 1999. Sediment control at lateral diversions: Limits and enhancements to vane use. Journal of Hydraulic Engineering 125(8): 862-870.

10. Davinroy, R. D. 1999. River Replication, Journal of Civil Engineering 60-63

11. Fares, Y. R., J. G. Herbertson. 1993. Behaviour of flow in a channel bend a side overflow (flood relief) channel, Journal of Hydraulic Research 31(3): 383-402.

12. Hussein, A. S. A. and K. V. H. Smith. 1986. Flow and bed deviation angle in curved open channels, Journal of Hydraulic Research 24(2): 93-108.

13. Johnson, P. A., R. D.Hey, M. Tessier and D. L. Rosgen. 2001. Use of vanes for control of scour at vertical wall abutments, Journal of Hydraulic Engineering, ASCE 127(9): 772-778.

14. Marelius, F., S. K. Sinha. 1998. Experimental investigation of flow past submerged vanes, Journal of Hydraulic Engineering, ASCE 124(5): 542-545

15. Nakato, T., J. F. Kennedy and D. Bauerly. 1990. Pump-station intake - shoaling control with submerged vanes, Journal of Hydraulic Engineering, ASCE 116(1): 119-128.

16. Nakato, T., F. L. gden. 1998. Sediment control at water intakes along sand- bed rivers, Journal of Hydraulic Engineering, ASCE 124(6): 589-596.

17. Neill, C. R. and B. J. Evans. 1997. Discussion by sediment control at water intake, Journal of Hydraulic Engineering, ASCE 122(7): 670-671.

18. Novak, P. and J. Cabelka. 1981. Models in Hydraulic Engineering. Physical Principles and Design Applications, Pitman Publication, London, UK. 


\title{
Laboratory Investigation of the Impact of Armor Dike Simple and L-shaped in Upstream and Downstream Intake of the Hydraulic Flow River and Intake Flow Rate
}

\author{
E. Geravandi ${ }^{1,2}$, A. Kamanbedast ${ }^{2}$, A. Masjedi ${ }^{2}$, M. Heidarnejad ${ }^{2}$ and A. Bordbar ${ }^{2}$
}

(Received: March 16-2017 ; Accepted: September 16-2017)

\begin{abstract}
Rivers has long been regarded as one of the most basic human water supplies. If the topography, a morphology, water requirements conditions, etc. allow water to be transferred to gravity, the use of the dike can have a significant impact on the flow rate and the sediment input to Intake. Dike design needs to consider several parameters such as position, length, type, etc. Using a good design can increase the input flow rate and reduce the sediment entering it. In this study, to evaluate the dike impact on flow hydraulic conditions in the Intake with different situations, 30, 45, 60 and 90 degrees two simple L-shaped dikes in the upstream and downstream Intake and for five inlet flows $(0.7,1.12,2.84,5.04$ and $6.23 \mathrm{Lit} / \mathrm{s}$ ) were considered in the laboratory flume made by the author as a physical model to simulate the flow of the basin; then different effects of the dike on the hydraulic flow were studied. The results of the tests showed that the L-shaped dike in the upstream and downstream Intake in the internal arc flume increased the inflow flow rate into the Intake. Also, the best angle of deviation for the maximum flow entered the Intake angle of 60 degrees.
\end{abstract}

Keywords: Intake, Dike, Physical model, Angle of deviation, Flow hydraulic, Simulation

1. Department of Water Science and Engineering, Khuzestan Science and Research Branch, Islamic Azad University (IAU), Ahvaz, Iran.

2. Department of Water Science and Engineering, Ahwaz Branch, Islamic Azad Univ. (IAU), Ahwaz, Iran.

*: Corresponding Author, Email: Ka57_amir@yahoo.com 